\title{
Assessment of the interaction of polycarboxylate superplasticizers in hydrated lime pastes modified with nanosilica or metakaolin as
}

\author{
pozzolanic reactives
}

\author{
I. Navarro-Blasco ${ }^{\mathrm{a}}$, M. Pérez-Nicolás ${ }^{\mathrm{a}}$, J.M. Fernández $^{\mathrm{a}}$, A. Duran ${ }^{\mathrm{a}}$, R. Sirera ${ }^{\mathrm{a}}$, J.I. Alvarez ${ }^{\mathrm{a}^{*}}$ \\ ${ }^{a}$ MIMED Research Group; Department of Chemistry and Soil Sciences, School of Sciences, University of \\ Navarra. Irunlarrea, 1.31008 Pamplona, Spain
}

Keywords: flowability; polycarboxylate; admixture; pozzolan; air lime mortar; zeta potential; nanosilica; metakaolin

\begin{abstract}
Two polycarboxylate ether copolymers were assessed as superplasticizers (SPs) for hydrated lime pastes modified with two reactive compounds, nanosilica (NS) and ceramic metakaolin (MK). Characterization of the molecular structure of the SPs by Size Exclusion Chromatography, XRD, FTIR and MALDI-TOF (Matrix Assisted Laser Desorption Ionization Time-of-Flight) mass spectrometry was performed. The structures of the polymers were seen to be star- and worm-like shapes. A close relationship was found between the molecular architecture and the flowability of the pastes, being the star-shaped plasticizer the most efficient. Zeta potential assessment allowed us to elucidate a steric hindrance as the main action mechanism for these polymers. The large specific surface area of nanosilica led to a large SPs consumption as compared with metakaolin with lower surface area. However, SPs in MK-lime samples were attached favourably on the C-S-H and aluminate hydrates, so that the dispersing action was greater with respect to NS-lime suspensions.
\end{abstract}




\section{Introduction}

The use of plasticizing admixtures in order to improve the handling of cement-based media has been extensively reported [1,2]. High-range water reducers or superplasticizers (SPs) act reducing the water demand and enhancing the flowability of the fresh mortars, yielding workable materials [3]. SPs present different chemical compositions, such as lignosulfonates, sulfonated melamine-based polymers or polycarboxylate-based compounds (PCE) [4]. The latter are belonging to the last generation of SPs and consist of a main linear backbone (polymethacrylic acid) with carboxylate groups, some of them grafted with side chains with ether functionalities (polyethylene oxide units) [5]. The length of both backbone and side chains can be variable, thus giving rise to a different effectiveness. In general, PCEs have been reported to show a comb-shaped, worm-shaped or even star-shaped molecular architecture structure, always as a function of their ratio between the main backbone and the side chain length [6]. In high alkaline $\mathrm{pH}$ systems (such as cement- or lime-based binders), carboxylic groups of these SPs are expected to be deprotonated as carboxylate groups. The extent of the plasticizing action as well as the dispersion maintaining ability is strongly ascribed to structural factors, such as the length of the backbone and of the lateral chains [7]. At the same time, an increase in the molecular weight is expected to enhance the adsorption of the PCE on the binding particles as well as its performance $[8,9]$.

Besides these aspects, the interaction of PCEs with the binding phases can induce several changes in the nucleation and growth of crystals, since PCEs can form complexes with $\mathrm{Ca}^{2+}$ ions, modifying the crystallization of Ca-rich compounds [10]. In addition, the dispersive effect inhibits the hydration kinetics leading to changes in the 
microstructure of the mortars. All these issues are related to the adsorption and compatibility between the admixture and the binder [9].

So far little attention has been devoted to the study of the performance of PCEs in limebearing pastes and mortars [11-13]. Lime-based dispersions can be used to obtain hydraulic mortars, which can be prepared either by the use of a natural hydraulic lime or by the incorporation of materials with pozzolanic activity, like metakaolin or nanosilica [14-16]. These two last compounds have shown the enhancement of several properties of air-lime based pastes and mortars: compressive strength, setting time and reduced microcracking, as a result of their filler effect and their reaction with $\mathrm{Ca}(\mathrm{OH})_{2}$ yielding C-S-H phases (for NS and MK additions) $[14,17]$ or aluminate-based compounds such as $\mathrm{C}_{2} \mathrm{ASH}_{8}$ and $\mathrm{C}_{4} \mathrm{AH}_{13}$ (just for $\mathrm{MK}$ additions) [18]. The widespread use of hydrated lime and pozzolan-hydrated lime pastes for paints, consolidant products, soil treatments and the obtaining of repair mortars and grouts, especially for architectural monuments of the Cultural Heritage, supports the interest of these materials. In the case of grouts, one of the most relevant features is to achieve a suitable flowability that allows the grout to fill voids providing a good continuity of the masonry system [19]. In order to design suitable hydrated lime pastes and mortars, the use of compatible and effective SPs seems to be imperative.

Therefore, to gain a better understanding on the behaviour of PCEs in lime-bearing pastes and mortars, the goal of this work is the assessment of the interaction between two different PCE admixtures and both plain hydrated lime and hydrated lime pastes modified upon the addition of pozzolans: nanosilica or metakaolin. The adsorption behaviour, the effectiveness of the polymeric admixtures in the increase of fluidity of these systems and the dispersion maintaining ability over the time will be evaluated and related to the polymer characteristics. 


\section{Materials and methods}

\subsection{Materials}

Both pozzolanic and pozzolan-free pastes were prepared by using a dry slaked lime (class CL 90-S according to European standard [20], supplied by CALINSA, Spain). The first pozzolan used was a colloidal silica suspension, nanosilica $(\mathrm{NS} ; \mathrm{pH}=9.68$, with a solid/liquid ratio of 0.28) as supplied by ULMEN Europa S.L. (Spain), with a specific surface area of $500 \mathrm{~m}^{2} \mathrm{~g}^{-1}$ and an average particle size of $50 \mathrm{~nm}$, as shown in the TEM micrograph of Fig. 1. This NS was selected because it was a superplasticizerfree suspension. The second pozzolan was metakaolin (MK), supplied by METAVER, with a specific surface area of $20 \mathrm{~m}^{2} \mathrm{~g}^{-1}$ and an average particle size of $4.5 \mu \mathrm{m}$, as depicted in the TEM images in Fig. 1. This is made of a calcined kaolinite so that this fact guarantees a high reactivity. Different weight percentages $(0,6,10$ and 20 wt. \% with respect to the weight of lime) of the pozzolans were added to obtain pastes in which the flowability and other properties were assessed.

Two different commercially available PCE-based superplasticizers were added in percentages of $0,0.25,0.50,0.75,1.00,1.25$ and $1.50 \%$ with respect to the weight of lime. These copolymers were obtained by grafting side chains of poly(ethyleneoxide) in a main backbone of polymethacrylate [21,22]. Both copolymers were of similar and relatively low molecular weight in order to study the influence of the molecular architecture of the polymers on the performance of the tested admixtures.

Given that the assayed additives were expected to have a strong influence on the fluidity of the fresh pastes, the water/lime ratio that provided a good workability in the control sample, was then chosen as a fixed ratio for all the remaining samples.

\subsection{Methods}




\subsubsection{Pastes preparation}

Lime, pozzolan (MK) and dry PCE admixture, when necessary, were blended for 5 min using a solid admixtures mixer BL-8-CA (Lleal S.A.). Water (and, when required, the other pozzolan as a nanosilica suspension) was then added and mixed for $90 \mathrm{~s}$ at low speed, in a Proeti ETI 26.0072 mixer.

\subsubsection{Experimental measurements}

The characterization and structural elucidation of SPs were carried out by elemental analysis, conductometric titration, X-ray diffraction, Fourier transform infraredattenuated total reflectance (FTIR-ATR) spectroscopy, refractive index size exclusion chromatography (RI-SEC) and MALDI-TOF (Matrix Assisted Laser Desorption Ionization Time-of-Flight) mass spectrometry.

Elemental analysis (weight percentages of $\mathrm{C}, \mathrm{H}$ and $\mathrm{N}$ ) was performed with a LECO CHN-900 analyzer. The carboxylate groups population present in each PCE was determined by conductometric titration. The conductivity measurements were carried out by means of an Orion 4-Star benchtop $\mathrm{pH} /$ conductivimeter (Thermo Scientific) using a $0.1 \mathrm{M} \mathrm{NaOH}$ solution. The anionic charge density supplied by carboxylate sites of assayed SPs was expressed in terms of meq per $g$ of polymer.

A Bruker D8 Advance diffractometer was used for XRD analysis, under conditions of a step size of $0.02^{\circ}$ and $1 \mathrm{~s}$ time/step, from $2^{\circ}$ to $80^{\circ}(2 \theta)$ with a $\mathrm{CuK} \alpha_{1}$ radiation. FTIR spectra were recorded with a Nicolet-Avatar 360 FTIR spectrometer equipped with Golden Gate ATR accessory and temperature control $\left(20-200^{\circ} \mathrm{C}\right)$. Spectra were collected over a range $4000-600 \mathrm{~cm}^{-1}$ with a resolution of $4 \mathrm{~cm}^{-1}$. Each spectrum was the result of averaging 100 scans. 
The molecular weight distribution of SPs was determined using size exclusion chromatography (SEC) coupled to refractive index (RI) detector (Optilab-TRex, Wyatt). Polymer solutions $\left(5 \mathrm{~g} \mathrm{~L}^{-1}\right)$ were filtered through a $0.45 \mu \mathrm{m}$ filter and injected to a series of three Waters columns (Waters, Milford, MA), Ultrahydrogel 2000, 250, and 120 with exclusion limits of $7.10^{6}, 8.10^{4}$, and $5.10^{3} \mathrm{~g} \mathrm{~mol}^{-1}$, respectively. A $0.1 \mathrm{M} \mathrm{NaCl}$ aqueous solution was used as eluent. A calibration with conventional standards of polyethylene oxide (PEO) and polyethylene glycol (PEG) covering a wide molecular weight range from 615 to $318,000 \mathrm{~g} \mathrm{~mol}^{-1}$ was employed.

MALDI-TOF mass spectra were recorded by using UltrafleXtreme III MALDI-TOF system (Bruker-Daltonics) operated in positive-linear mode (m/z range of 100-7000 Da). The matrix used was composed of $10 \mu \mathrm{g} \mu \mathrm{L}^{-1}$ of $\alpha$-cyano-4-hydroxycinnamic acid $(\mathrm{HCCA})$ in $50 \%(\mathrm{v} / \mathrm{v})$ acetonitrile $(\mathrm{ACN})$. A sample/matrix solution $(1 \mu \mathrm{L}$, ratio $1: 1 \mathrm{v} / \mathrm{v})$ was deposited onto the MALDI sample probe.

To determine the consistency of the suspensions either viscosimetry or mini-slump flow test can be used. The latter was selected to assess the flowability of the pastes. A truncated metallic cone was filled with the sample; then, the metallic cone was removed and the cone-shaped sample was vertically lifted (15 strokes of the flow table) so that the gravity allowed the sample to slump down and a quantitative measure of the slump was recorded $[23,24]$. In order to assess the dispersion maintaining ability over the time, this test was additionally carried out after 0, 30, 60, 90, 120 and 150 min after the preparation of the suspensions. The setting time of the pastes was calculated according to the norm [25].

All sorption experiments for assayed SPs in both individual compound pastes $(1 \mathrm{~g}$ per $25 \mathrm{~mL}$ of water) and in lime-pozzolan systems ( $5 \mathrm{~g}$ of lime and pozzolanic additive at 6 , 10 and 20 wt.\% with respect to lime in $25 \mathrm{~mL}$ of water) were conducted in batch 
reactors. The mixtures were stirred for 1 hour in order to reach equilibration and, subsequently, were centrifuged at $8000 \mathrm{~g}$ for $15 \mathrm{~min}$ and the supernatant was collected and filtered through $0.45 \mu \mathrm{m}$ PTFE filters for the measurement of the remaining polymer. The amount of SPs adsorbed onto the particles was determined by difference between initially added and final remaining concentration of the superplasticizer found in the equilibrium solution, as quantified by ultraviolet-visible spectrophotometry. The Freundlich model $\left(\mathrm{q}=\mathrm{K} \cdot \mathrm{C}^{1 / \mathrm{n}}\right)$ were used to fit the adsorption data, where, $\mathrm{q}$ represents the amount of PCE sorbed by the solid phase $\left(\mathrm{mg} \mathrm{g}^{-1}\right), \mathrm{C}$ is the concentration of PCE in the solution $\left(\mathrm{mg} \mathrm{L}^{-1}\right)$ after equilibration, while $\mathrm{K}$ and $1 / \mathrm{n}$ are the Freundlich constants. The interaction between the superplasticizer additive and the lime and/or pozzolans was studied by means of the measurement of the zeta potential in the solid/liquid interface [4,26,27]. To this aim, individual (25 $\mathrm{g}$ per $140 \mathrm{~mL}$ of water) or multicomponent suspensions ( $7 \mathrm{~g}$ of lime and $25 \mathrm{~g}$ of either NS or MK per $140 \mathrm{~mL}$ of water that were allowed to react for $30 \mathrm{~min}$ to ensure the pozzolanic reaction to take place) were prepared. When necessary, $1 \% \mathrm{w} / \mathrm{v}$ PCE solutions were used as titrants. An electroacoustic-based zeta potential analyser (ZetaProbe of Colloidal Dynamics), which allows to accurately measure the zeta potential of concentrated pastes, was used [28].

\section{Results and discussion}

\subsection{Characterization of the polycarboxylate ester copolymers}

The structural and compositional characteristics of the two superplasticizers were investigated. Size-exclusion chromatography data allowed us to obtain the weightaverage molecular weight $(\mathrm{Mw})$, the number-average molecular weight $(\mathrm{Mn})$ and the polydispersity index, i.e. the distribution of the molecular weight for each polymeric fraction (Table 1). According to the molecular mass distribution obtained from SEC 
chromatograms, PCE1 showed an almost unimodal distribution around $5000 \mathrm{~g} \mathrm{~mol}^{-1}$, whereas PCE2 distribution depicted a clear bimodal pattern, with the most intense peak at ca. $2000 \mathrm{~g} \mathrm{~mol}^{-1}$ (Supplementary material Fig. S1).

Although the PCE1 sample was more crystalline, XRD analysis of both superplasticizers offered similar diffraction peaks, showing in the two cases the presence of polyethylene glycol (PEG) (Supplementary material Fig. S2), which was the main component of the grafted side chains. Besides, the PCE1 showed the presence of a phase of PEG with high molecular weight that is absent in the diffractogram of PCE2.

Acid-base titrations carried out in solutions of the two polymers showed the anionic charge densities of these superplasticizers, representing the amount of $\mathrm{COO}^{-}$ functionalities per gram of polymer. This parameter indicates the degree of esterification of the backbone of the polymer chain: the higher the anionic charge density, the lower the ester content in the polymer. PCE2 presented a larger amount of $\mathrm{COO}^{-}$groups, as proved by its higher anionic charge density (Table 1). Functional groups in superplasticizers were further verified by FTIR-ATR experiments. The absorption bands at the spectral range between $1750 \mathrm{~cm}^{-1}$ and $1600 \mathrm{~cm}^{-1}$ (Supplementary material Fig. S3) confirmed the presence of carbonyl groups (either from esterification of some carboxylic groups of the backbone - polymethacrylic acid or by the carboxylic functions themselves remaining without grafting) [29,30], mainly in PCE2. The existence of C-O-C bonds in both plasticizers was testified by bands at the specific frequencies of stretching vibrations for ether groups, sited at $950-1150 \mathrm{~cm}^{-1}$ wavenumber [29-31]. C-H stretching vibration absorption bonds appeared at $2880 \mathrm{~cm}^{-1}$ (Supplementary material Fig. S3).

Finally, the use of MALDI-TOF mass spectrometry gave important parameters regarding the architecture of the molecular structure of the two superplasticizers, as it is 
an analytical technique with capability to provide information about molecular mass, end group and branching of the polymers [32]. MALDI-TOF is able to provide a mass spectrum reflecting the oligomers distribution and their relative amounts. Polymers, such as those tested in this work, undergo degradation in MALDI-TOF resulting in fragment ion peaks in the mass spectrum. As it can be inferred from the spectra (Fig. 2), the wide range of signal intensities (mass-to-charge - $\mathrm{m} / \mathrm{z}$ - ratios) for PCE1, as well as the position of the most intense signal, suggest that this superplasticizer has, respectively, side chains of greater length and higher $\mathrm{Mw}$, in accordance with the XRD analysis observations (Supplementary material Fig. S1).

The asymmetrical distribution (especially the low $\mathrm{m} / \mathrm{z}$ tail) indicates the detection of broad population of oligomers arising from the cleavage of the polymer molecule (mainly ascribed to the side chains - PEG - fragmentation, which takes place at the oxygen-carbon bond in the repeated ethylene oxide units. This fragmentation of the PEG can be identified by the secondary peak series) [33]. This fact can be confirmed by the mass differences (width between each one of the oligomer peaks) in the mass distribution spectrum that matches the molecular weight of an ethylene oxide unit ( $44 \mathrm{~g}$ $\mathrm{mol}^{-1}$ ) (see the expanded distribution in the upper part of Fig. 2) [34]. However, the PCE2 polymer, with a narrower $\mathrm{m} / \mathrm{z}$ distribution centred at lower $\mathrm{m} / \mathrm{z}$ ratio (Fig. 2), seems to be made of shorter side chains (with identical width between the oligomer peaks) and this dispersing agent shows a lower Mw. In the spectrum of PCE2, there is no evidence of either low or high $\mathrm{m} / \mathrm{z}$ tails.

These findings confirmed the Mw data obtained by SEC and allowed us to set up two different molecular structures for these superplasticizers, showed in the scheme of Fig. 3: PCE1, with lower anionic charge density but with larger Mw and longer side chain length, would resemble a star-shaped polymer, with a relatively short main backbone 
(accounting for its low anionic charge density along this main chain) and with longer side chains; PCE2, with higher anionic charge density but lower Mw and shorter side chain length, would appear to be a worm-like polymer, with a main backbone proportionally longer (with more $\mathrm{COO}^{-}$functionalities) than its shorter side chains.

\subsection{Dispersion effectiveness}

In plain air lime-based mixtures, the presence of the tested SPs increased the flowability of the pastes (Fig. 4). PCE1 improved the flowability beyond the limits of the flow table test, yielding a slump larger than $300 \mathrm{~mm}$ for all the tested dosages. This copolymer turned out to be more effective than PCE2 in increasing the fluidity of the pastes, since even at the lowest dosage $(0.25 \%)$, the slump reached the maximum value.

The study of the dispersing behaviour was also carried out in the presence of the pozzolanic additives. When nanosilica was added, the flowability of PCE-free lime pastes underwent a reduction (Fig. 5). This fact can be explained owing to the small particle size of NS, which increases the water demand to achieve a similar consistency. The higher the amount of NS in air lime media, the lower the flowability of the pastes. In these pastes, the PCE1 dispersing agent was also more effective as plasticizer, yielding, for similar dosages, larger values of slump.

In the presence of metakaolin, the slump reduction in PCE-free pastes was not as strong as in the case of nanosilica (Fig. 5). The slump of the PCE-free lime-MK pastes was slightly lower (pastes with 6 and $10 \mathrm{wt} . \%$ of MK) or even similar (pastes with $20 \mathrm{wt} . \%$ of MK) to that observed for plain lime pastes (Fig. 5). The higher slump values of MKbearing samples when compared with NS-bearing dispersions could be explained taking 
into account the differences in the particle average size (because the larger particle size of the MK led to a lower water demand) and a certain lubricant effect, that allowed the particles to reduce their friction forces, thus increasing the fluidity [35]. In this line, the low water demand of samples with MK has been previously reported [36]. Also in these MK-lime pastes PCE1 copolymer showed the best plasticizing effect as compared with PCE2.

One of the most important characteristics of the performance of superplasticizers is their dispersion maintaining ability over the time. This parameter can be evaluated by assessing the slump loss over the time. Fig. 6 shows the experimental fluidity loss during the first 150 min after the mixing for plain lime pastes (Fig. 6a), lime with 20 wt.\% NS and lime with 20 wt.\% MK pastes (Fig. 6b), modified upon the addition of $0.5 \%$ of superplasticizer. In all these systems, PCE1 showed the largest dispersing ability over the time. Plain lime and MK-lime suspensions with PCE1 offered a large fluidity even after $150 \mathrm{~min}$. Conversely, NS-bearing pastes showed a low fluidity and presented no strong changes over the time.

Setting time in pozzolan-lime pastes can be considered as a good indicator of the speed of the pozzolanic reaction and further hydration of the compounds. In this work, the setting time measurements provided experimental data about the effect of the SPs on the hardening process of the pastes. Plain air lime samples harden through carbonation of the $\mathrm{Ca}(\mathrm{OH})_{2}$ to yield $\mathrm{CaCO}_{3}$, whereas in pozzolan-lime mixtures the pozzolanic reaction with the subsequent formation of C-S-H (NS and MK) and aluminate hydrates (just $\mathrm{MK})$ is the main responsible for the stiffening of the pastes. From the experimental results, it was observed that, in general, irrespective of the media and of the superplasticizer, the higher the dosage of superplasticizer the stronger the delay in the setting time. Fig. 7a shows the behaviour of plain lime pastes: above $0.50 \%$, the delay in 
setting time dramatically increased for PCE1. For PCE2, the setting time delay increased in a more uniform way as a function of the copolymer dosage. From these data, it can be concluded that mixtures with large SP dosages can lead to non-applicable samples for grouts owing to the severe delay in the setting time. The dispersing action of these admixtures would explain the setting time delay: the presence of the copolymer hinders the irreversible agglomeration of the formed particles, which should take place to harden the lime paste [37]. The stronger plasticizing effect of the PCE1 led to a more pronounced delay. With respect to those samples with a pozzolanic addition, in general, the presence of NS induced a delay that could be attributed to the slower pozzolanic reaction of this admixture as compared with MK (Fig. 7b). In line with these results, it had been reported that high dosages of dispersing agents can show, as a drawback, a marked delay in the setting time for cement-based materials [29,38]. As a matter of fact, samples with additives and SPs added in dosages above $0.50 \mathrm{wt}$ \% produced setting time delays ever so long as to make them unpractical to register: for this reason, Fig. $7 \mathrm{~b}$ only shows setting times for samples containing SPs doses up to $0.50 \mathrm{wt} . \%$.

\subsection{Action mechanism: adsorption and zeta potential assessment}

Adsorption performance of both superplasticizers in different pastes and zeta potential measurements were carried out in order to assess the dispersing effectiveness and to ascertain possible changes on the surface charge of the lime, NS or MK ceramic particles and formed compounds.

\subsubsection{Plain nanosilica dispersions}

With respect to assays carried out onto plain nanosilica, it was observed that both copolymers were fixed: average percentages of $10 \%$ of PCE1 and $37 \%$ of PCE2 were 
adsorbed, at a 0.5 to $6 \mathrm{~g} \mathrm{~L}^{-1}$ equilibrium concentration range of each of the assayed SPs. The zeta potential evolution of a NS suspension titrated with individual solutions of both polymers is depicted in Fig. 8. In this suspension of NS, with alkaline $\mathrm{pH}(9.71)$ the surface charge is expected to be negative, owing to the deprotonation of the silanol$\mathrm{SiOH}$ groups at this $\mathrm{pH}$. According to the model of the structure of electric double layers (EDL) around colloidal particles reported elsewhere [39], the zeta potential is measured in the shear plane of the outer Helmholtz layer. In the present system, that shear plane may be expected to be made of hydroxyl anions counteracting the positive charge of cations adsorbed onto the negatively charged surface of the nanosilica particles, following the scheme showed in Fig. 9. As a result, the zeta potential of the NS should be negative, as experimentally confirmed $(-50 \mathrm{mV})$. In spite of the fact that both SPs are expected to be negatively charged at the alkaline $\mathrm{pH}$ of the experimental system due to the carboxylate functions located at their backbones, both copolymers were adsorbed onto the negatively charged NS. A substitution process, in which some of the $\mathrm{OH}^{-}$anions were released and some of the polymer units were adsorbed onto the NS, can be invoked as an explanation for this adsorption (Fig. 9). Similar phenomena have been reported for the adsorption of polycarboxylate ethers onto different surfaces, including calcium carbonate and silica fume $[6,40]$. In the current work, the adsorption of the copolymers onto NS would be mainly driven by the increase in entropy caused by the release of $\mathrm{OH}^{-}$anions during the substitution mechanism. In order to give an explanation to the zeta potential evolution towards less negative values, the molecular architecture of the polymers has to be considered: the adsorption of the polymers produced a broadening of the outer Helmholtz layer and, accordingly, induced a weaker potential of the double layer that resulted in a less negative zeta potential (Fig. 9), which was measured at the displaced shear plane (slipping plane between the movable and the 
stationary phase) $[39,41]$. The longer the side chains of the polymer, the more marked the displacement of the shear plane (Fig. 9) and the larger the effect observed on the zeta potential: PCE1, with longer side chains, shifted the zeta potential from -50 to -33 $\mathrm{mV}$, while PCE2, with shorter side chains, modified the zeta potential just up to -47 $\mathrm{mV}$. Besides, the different molecular structure of the copolymers accounted for the different amounts adsorbed: PCE1, with longer side chains and low anionic charge density in the backbone (star-shaped polymer), was less adsorbed, whereas the wormlike PCE2, with shorter side chains and more carboxylate groups in the backbone, was adsorbed to a larger extent. The backbone of star-like polymers can be assumed to adsorb perpendicularly to the surface of the particles, as depicted in Fig. 9, showing a high degree of steric hindrance caused by the spatial distribution of the grafted chains, resulting in a low surface loading. On the contrary, polymers with shorter side chains tend to undergo a flat adsorption of the backbone (parallel to the particle surface), yielding a larger amount of adsorbed polymer, as it was observed for PCE2 and showed in Fig. 9.

\subsubsection{Plain metakaolin dispersions}

In the case of a suspension of metakaolin in water, adsorption assays showed that PCE1 was not adsorbed onto the MK ceramic particles. Conversely, the percentage of adsorbed PCE2 onto MK was greater (average percentage of 52\%) than that adsorbed onto NS under identical experimental conditions. An acidic $\mathrm{pH}$ (5.6) was measured for this MK aqueous dispersion and appears to be critical to explain the adsorption behaviour. MK can be described as a 1:1 TO clay (tetrahedral silica layer and octahedral

alumina sheet), with permanent negative charges in the faces (minor isomorphic substitution in the $\mathrm{T}$ faces). In addition, $\mathrm{pH}$-dependent ionizable groups (silanol and 
mainly aluminol (Al-OH) groups) can be found in both the broken edges and the exposed hydroxyl-terminated planes [42]. At the experimental $\mathrm{pH}$ (5.6) of the MK dispersion (below the point of the zero net proton charge, PZNPC, which for MK can be estimated at a $\mathrm{pH}$ of ca. 6-6.5), the more reactive aluminol groups can be partially protonated to form $\mathrm{Al}-\mathrm{OH}_{2}{ }^{+}$, thus yielding edges positively charged [43]. A cloud of compensating counterions forms the electric double layer around these surfaces. Interaction between positive edges and negative basal faces is thus possible, giving rise to the heterocoagulation of the MK in a card-house shape, as observed in TEM examination of this MK dispersion (Fig. 1) [44].

However, as the edges surface area turns out to be lower in comparison with the basal planes area, the overall zeta potential was negative $(-22 \mathrm{mV})$ for this suspension (Fig. 10). The fact that PCE1 was not absorbed onto MK, can be due to its low population of carboxylate functions in its short main backbone at the acidic $\mathrm{pH}$ of the dispersion: a relevant part of the $\mathrm{COO}^{-}$functions was protonated, thus reducing the anionic charge density of the copolymer, hindering its adsorption interaction either by electrostatic interaction or by substitution process. Besides, the backbone charge was further sterically shielded by the long side chains, thus contributing to the adsorption hindrance. The experimental finding of the negligible adsorption of this PCE1 is also helpful to dismiss the formation of hydrogen bonds as a way of explanation of the adsorption of polycarboxylates onto this material. On the other hand, the higher anionic charge density (larger number of $\mathrm{COO}^{-}$functions) of the PCE2 molecule allowed it to show a significant negative charge in its backbone, even at the acidic $\mathrm{pH}$ of the experimental dispersion. Its previously described flat adsorption favoured a stronger interaction with the substrates: the polymer units could be attached either to the counterions of the outer Helmholtz layer of the basal faces (through a substitution process) or to the positively 
charged edges (by means of electrostatic attraction, mainly driven by enthalpic contribution). The displacement of the zeta potential of the MK towards more negative values when PCE2 was added is in agreement with the kinetically fostered later possibility.

\subsubsection{Plain hydrated lime pastes}

In the hydrated lime-bearing pastes, experimental data analysis from the adsorption tests of the copolymers adjusted preferentially to a Freundlich model. Experimental data linearized according to the corresponding algorithm, allowed us to derive the Freundlich equation, from which the adsorbed amount of either copolymer could be plotted. In general, the larger the concentration of the SP assayed, the greater the extent of the adsorption. Adsorption tests showed that PCE2 was adsorbed in a 3- to 4-fold when compared with PCE1, in plain air lime samples (Fig. 11).

The adsorption interaction for the polycarboxylate-based superplasticizers may be explained by considering the positive zeta potential values showed by air lime suspensions, as depicted in Fig. 12. Portlandite dispersions, owing to the high $\mathrm{pH}$ (experimental value of 12.6) and to the presence of $\mathrm{Ca}^{2+}$ cations, yielded positive zeta potential ranging from +10 to $+20 \mathrm{mV}$. The carboxylic functions located in the backbone of the tested copolymers appeared deprotonated and negatively charged at that alkaline $\mathrm{pH}$, so that the electrostatic attraction would explain the adsorption of polycarboxylates. The asymptotic trends of the zeta potential in Fig. 12 would indicate that the systems reached the saturation level. There was not any difference between PCE1 and PCE2 regarding the zeta potential evolution in plain lime media: as explained above, the displacement of the shear plane and the subsequent zeta potential reduction 
caused by PCE1 could have been compensated for its lower anionic charge density, thus yielding similar values to those measured for PCE2.

\subsubsection{Hydrated lime pastes with pozzolanic additives}

When the reactive NS or MK was present, the pozzolanic reaction gave rise to the formation of C-S-H and, in the case of MK, also to aluminate-based compounds [18]. Despite the reaction between a compound with positive zeta potential (portlandite) and other with negative zeta potential (NS or MK), the resulting products offered strongly positive values of zeta potential. This fact can be evidenced by the zeta potential evolution of air lime pastes in which increasing amounts of the pozzolanic additive were added (Fig. 13): the pozzolanic reaction compounds showed positive values of the zeta potential since the alkaline $\mathrm{pH}$ caused deprotonation of their silanol and aluminol groups and the accumulation of multivalent counterions (mainly $\mathrm{Ca}^{2+}$ ) in the electric double layer gave rise to an overcharging that resulted in an apparent charge reversal (positive zeta potential) [45]. This zeta potential evolution was also an indicator of the pozzolanic reaction that took place between lime and any of the pozzolanic additives. Fig. 13 shows that, even though the zeta potential reached similar values (ca. $+50 \mathrm{mV}$ ), the reactivity of the two pozzolans was different: MK, showing a zeta potential curve with a positive slope, appeared to react faster and in a more uniform way than NS. NS showed a turning point after the addition of $30 \mathrm{~mL}$ of NS dispersion and presented a curve that suggests an asymptotic zeta potential slightly above $+50 \mathrm{mV}$ and a subsequent limited extent of the reaction. In this line, setting time measurements (previously discussed in section 3.2) also indicated that, in general, the presence of NS induced a delay that could be attributed to the slower reaction. 
When negatively charged polycarboxylates were incorporated into these lime-NS or lime-MK pastes, they were able to be adsorbed onto these highly positive layers of calcium counterions of the hydrates, thus justifying the improvement in the adsorption amounts as compared with the plain lime media (Fig. 11). However, the effect of the copolymers adsorption on the zeta potential was clearly different (Fig. 14). The sharpest zeta potential reduction was measured for lime-MK pastes, achieving asymptotic values around $+10 \mathrm{mV}$. However, lime-NS pastes showed a more mitigated decrease but without reaching the asymptotic region. Specific surface area, chemical differences and kinetics of the pozzolanic reaction in those systems accounted for the differences in zeta potential and in the dispersing effectiveness.

Both copolymers showed better plasticizing effect when added to lime-MK pastes (section 3.2), in spite of their lower adsorption measured through the adsorption isotherms (Fig. 11). As showed in Fig. 5, higher doses of superplasticizers were required in lime-NS than in lime-MK pastes to achieve a similar flowability. This high consumption of polycarboxylates can be explained taking into account the high specific surface area (ca. $500 \mathrm{~m}^{2} \mathrm{~g}^{-1}$, caused by the low particle size of the nanosilica, ca. $50 \mathrm{~nm}$ ) (Fig. 1). This large surface area provided an outstanding amount of adsorption sites for the copolymers, as proved by the high percentages of superplasticizers adsorbed on plain NS dispersions and on lime-NS media. In this sense, great adsorption of polycarboxylates onto silica-based materials, like silica fume, had already been reported $[1,40]$. However, these adsorption sites provided by NS were not "active" sites in connection with the C-S-H dispersion: the higher the percentage of polymer adsorbed onto NS, the lower the percentage of polymer adsorbed onto C-S-H compounds. Therefore, the overall zeta potential, which can be preferentially ascribed to the EDL around C-S-H, was modified to a rather limited extent (from $+60 \mathrm{mV}$ to a positive value 
ranging from 40-49 $\mathrm{mV}$ ) (Fig. 14). The zeta potential shift towards more negative values was caused by: (i) the compensation of the positive charge of the external layer of $\mathrm{Ca}^{2+}$ ions by the negatively charged polycarboxylate units; and (ii) the simultaneous displacement of the shear plane of the outer Helmholtz layer owing to the side chains of the copolymers. The former factor was more important for PCE2 whilst the later one was predominant in the case of PCE1. Conversely, MK did not present such a large number of adsorption sites: for example, plain MK systems showed no affinity for PCE1, as previously discussed. This fact is ascribed to the lower specific surface area (ca. $\left.20 \mathrm{~m}^{2} \mathrm{~g}^{-1}\right)$ and a higher average particle size $(4.5 \mu \mathrm{m})$ of MK as compared with NS. Instead of being adsorbed onto MK, the superplasticizer molecules would be mainly attached to the C-S-H and aluminate hydrates compounds formed during hydration. Therefore, the tested SPs, despite their lower adsorption onto these MK-lime pastes, showed a large degree of plasticizing effectiveness. At the same time, the effect of the attached polycarboxylates onto EDL was, consequently, sharper, as proved by the clear reduction of the zeta potential (Fig. 14). The asymptotic zeta potential curve suggests that the EDL of the hydrated compounds is near the saturation value. The experimentally proved faster reactivity of the MK in lime media also contributed to reduce the number of "inactive" sites, given that $\mathrm{MK}$ reacted rapidly with $\mathrm{Ca}(\mathrm{OH})_{2}$. In this line, marked zeta potential drops were reported for $\mathrm{MK}$ dispersions after polycarboxylates adsorption [2].

The SPs attachment onto NS would retard the pozzolanic reaction between NS and $\mathrm{Ca}(\mathrm{OH})_{2}$. This fact was experimentally proved by means of the setting time measurements: in lime-NS pastes, the increasing amounts of superplasticizers caused stronger delays in the setting time as compared with lime-MK samples (Fig. 7). 
The different molecular architecture of the two tested copolymers played a key role in order to explain their dispersing performance. Taking into account that both are copolymers of relatively low molecular weight, in the tested media star-shaped polycarboxylates with short backbone and low anionic charge density but with long side chains have been proved to be more effective. In spite of the low adsorbed amounts of PCE1, its dispersing action was higher and allows to design flowable lime mortars and grouts with lower dosage of plasticizing agent. Regarding the zeta potential of the limeMK pastes with SPs, within the range of absence of electrostatic colloidal stability $(+20$ to $-20 \mathrm{mV}$ ) (Fig. 14), and the experimental efficiency of these SPs tested in this work, it can be concluded that the steric hindrance was then the main factor explaining the effect of these superplasticizers.

\section{Conclusions}

The polymer with the shortest backbone and lowest anionic charge density but with the longest side chains (star-shaped molecule) has been found to provide the largest plasticizing effect in the assayed lime pastes. At the same time, the consumption of this superplasticizer was the lowest, as proved by the low amount adsorbed. This polymer showed the best dispersion maintaining ability over the time and high doses of it led to the strongest delays in the setting time.

Conversely, the worm-like copolymer, with a longer backbone and larger population of carboxylate groups but with shorter grafted lateral chains, showed a high rate of consumption (large amount adsorbed) but the worst dispersing performance.

In the tested hydrated lime pastes, the presence of nanosilica, with large specific surface

area $\left(500 \mathrm{~m}^{2} \mathrm{~g}^{-1}\right)$, provided a high number of "inactive" adsorption sites for the 
polycarboxylates units, thus reducing the amount of polymer attached to C-S-H phases and the dispersing effectiveness.

The incorporation of metakaolin, with a lower surface area $\left(20 \mathrm{~m}^{2} \mathrm{~g}^{-1}\right)$, caused a decrease in the overall polymer adsorption but yielded a more effective dispersion performance due to the fact that the polymer units preferentially anchored onto C-S-H and aluminate hydrates.

Among the tested mixes, the combination of the PCE1 (star-shaped polymer) with metakaolin as pozzolanic agent provided the best flowability in order to its use as grout. Restoration mortars could be designed by using adequate ratios of lime, pozzolanic addition and superplasticizer according to the experimental results.

The main mechanism that explained the action of these copolymers was seen to be mainly steric hindrance, through side chains of the polymers.

\section{Acknowledgements}

The authors want to thank CTH Navarra, ULMEN, Lapiberia and Calinsa S.A. Navarra for the material supplied. Assistance of Dr. J. Calvo (CIC bioGUNE) in the MALDITOFF analysis is greatly acknowledged. This work was fully funded by Fundación Universitaria de Navarra under grant FUNA2013-15108402. We are also grateful to LURESA for providing complementary funding under grant LUR-2010.

\section{References}

1. Hommer H. Interaction of polycarboxylate ether with silica fume.

J Eur Ceram Soc 2009;29:1847-53. 
2. Li Y, Zhang Y, Zheng J, Guo H, Yang C, Li Z, et al. Dispersion and rheological properties of concentrated kaolin suspensions with polycarboxylate copolymers bearing comb-like side chains. J Eur Ceram Soc 2014;34:137-46.

3. Autier C, Azéma N, Boustingorry P. Using settling behaviour to study mesostructural organization of cement pastes and superplasticizer efficiency, Colloids Surf Physicochem Eng Aspects 2014;450:36-45

4. Papo A, Piani L. Effect of various superplasticizers on the rheological properties of Portland cement pastes. Cem Concr Res 2004;34:2097-101.

5. Plank J, Sachsenhauser B. Experimental determination of the effective anionic charge density of polycarboxylate superplasticizers in cement pore solution. Cem Concr Res 2009;39:1-5.

6. Plank J, Sachsenhauser B, de Reese J. Experimental determination of the thermodynamic parameters affecting the adsorption behaviour and dispersion effectiveness of PCE superplasticizers. Cem Concr Res 2010;40:699-709.

7. Puertas F, Santos H, Palacios M, Martínez-Ramírez S. Polycarboxylate superplasticiser admixtures: effect on hydration, microstructure and rheological behaviour in cement pastes. Adv Cement Res 2005;17:77-89.

8. Andersen PJ, Roy DM, Gaidis JM. The effect of superplasticizer molecular weight on its adsorption on, and dispersion of, cement, Cem Concr Res 1988;18:980-6,

9. Yamada K, Takahashi T, Hanehara S, Matsuhisa M. Effects of the chemical structure on the properties of polycarboxylate-type superplasticizer, Cem Concr Res 2000;30:197-207

10. Plank J, Zhimin D, Keller H, Hössle F v., Seidl W. Fundamental mechanisms for polycarboxylate intercalation into $\mathrm{C}_{3} \mathrm{~A}$ hydrate phases and the role of sulfate present in cement. Cem Concr Res 2010;40:45-57.

11. Seabra MP, Paiva H, Labrincha JA, Ferreira VM. Admixtures effect on fresh state properties of aerial lime based mortars. Constr Build Mater 2009;23:1147-53.

12. Arizzi A, Cultrone G. Aerial lime-based mortars blended with a pozzolanic additive and different admixtures: A mineralogical, textural and physicalmechanical study. Constr Build Mater 2012;31:135-43.

13. Fernández JM, Duran A, Navarro-Blasco I, Lanas J, Sirera R, Alvarez JI. Influence of nanosilica and a polycarboxylate ether superplasticizer on the performance of lime mortars. Cem Concr Res 2013;43:12-24.

14. Alvarez JI, Fernández JM, Navarro-Blasco I, Duran A, Sirera R. Microstructural consequences of nanosilica addition on aerial lime binding materials: Influence of different drying conditions. Mater Charact 2013;80:36-49. 
15. Andrejkovičová S, Velosa AL, Ferraz E, Rocha F. Influence of clay minerals addition on mechanical properties of air lime-metakaolin mortars. Constr Build Mater 2014;65:132-9.

16. Silva AS, Gameiro A, Grilo J, Veiga R, Velosa A. Long-term behavior of limemetakaolin pastes at ambient temperature and humid curing condition. Appl Clay Sci 2014;88-89:49-55.

17. Vejmelková E, Keppert M, Keršner Z, Rovnaníková P, Černý R. Mechanical, fracture-mechanical, hydric, thermal, and durability properties of lime-metakaolin plasters for renovation of historical buildings. Constr Build Mater 2012;31:22-8.

18. Rojas MF, Cabrera J. The effect of temperature on the hydration rate and stability of the hydration phases of metakaolin-lime-water systems. Cem Concr Res 2002;32:133-8.

19. Baltazar LG, Henriques FMA, Jorne F, Cidade MT. Combined effect of superplasticizer, silica fume and temperature in the performance of natural hydraulic lime grouts. Constr Build Mater 2014;50:584-97.

20. European Committee for Standardization UNE-EN 459-1. Building lime. Part 1: definition, specification and conformity criteria. CEN: Brussels. 2011.

21. Yamada K, Ogawa S, Hanehara S. Controlling of the adsorption and dispersing force of polycarboxylate-type superplasticizer by sulfate ion concentration in aqueous phase. Cem Concr Res 2001;31:375-83.

22. Ma B, Ma M, Shen X, Li X, Wu X. Compatibility between a polycarboxylate superplasticizer and the belite-rich sulfoaluminate cement: Setting time and the hydration properties. Constr Build Mater 2014;51:47-54.

23. European Committee for Standardization UNE-EN 1015-3. Methods of test for mortar for masonry. Part 3: Determination of consistence of fresh mortar (by flow table); CEN: Brussels. 2000.

24. Bouvet A, Ghorbel E, Bennacer R. The mini-conical slump flow test: Analysis and numerical study. Cem Concr Res 2010;40:1517-23.

25. European Committee for Standardization UNE-EN 1015-9. Methods of test for mortar for masonry. Part 9: Determination of workable life and correction time of fresh mortar; CEN: Brussels. 2000.

26. Zhang D, Ju B, Zhang S, He L, Yang J. The study on the dispersing mechanism of starch sulfonate as a water-reducing agent for cement. Carbohydr Polym 2007;70:363-8.

27. Zhang D, Ju B, Zhang S, Yang J. The study on the synthesis and action mechanism of starch succinate half ester as water-reducing agent with super retarding performance. Carbohydr Polym 2008;71:80-4. 
28. Srinivasan S, Barbhuiya SA, Charan D, Pandey SP. Characterising cementsuperplasticiser interaction using zeta potential measurements. Constr Build Mater 2010;24:2517-21.

29. Janowska-Renkas E. The effect of superplasticizers' chemical structure on their efficiency in cement pastes. Constr Build Mater 2013;38:1204-10.

30. Ma S, Zhao P, Guo Y, Zhong L, Wang Y. Synthesis, characterization and application of polycarboxylate additive for coal water slurry. Fuel 2013;111:64852.

31. Zhu J, Zhang G, Miao Z, Shang T. Synthesis and performance of a comblike amphoteric polycarboxylate dispersant for coal-water slurry. Colloids Surf Physicochem Eng Aspects 2012;412:101-7.

32. Wetzel SJ, Guttman CM, Girard JE. The influence of matrix and laser energy on the molecular mass distribution of synthetic polymers obtained by MALDI-TOFMS. Int J Mass Spectrom 2004;238:215-25.

33. Zhu H, Yalcin T, Li L. Analysis of the accuracy of determining average molecular weights of narrow polydispersity polymers by Matrix-Assisted Laser Desorption Ionization Time-of-Flight Mass Spectrometry. J Am Soc Mass Spectrom 1998;9:275-81.

34. Guérandel C, Vernex-Loset L, Krier G, De Lanève M, Guillot X, Pierre C, et al. A new method to analyze copolymer based superplasticizer traces in cement leachates. Talanta 2011;84:133-40.

35. Sonebi M. Rheological properties of grouts with viscosity modifying agents as diutan gum and welan gum incorporating pulverised fly ash. Cem Concr Res 2006;36:1609-18.

36. Dvorkin L, Bezusyak A, Lushnikova N, Ribakov Y. Using mathematical modeling for design of self compacting high strength concrete with metakaolin admixture. Constr Build Mater 2012;37:851-64.

37. Rodríguez-Navarro C, Ruiz-Agudo E, Ortega-Huertas M, Hansen E. Nanostructured and irreversible coloidal behaviour of $\mathrm{Ca}(\mathrm{OH})_{2}$ : implications in cultural heritage conservation. Langmuir 2005;21:10948-57

38. Zhang M, Sisomphon K, Ng TS, Sun D J. Effect of superplasticizers on workability retention and initial setting time of cement pastes. Constr Build Mater 2010;24:1700-7.

39. Plank J, Vlad D, Brand A, Chatziagorastou P. Colloidal chemistry examination of the steric effect of polycarboxylate superplasticizers. Cement International 2005;3:100-10. 
40. Burgos-Montes O, Palacios M, Rivilla P, Puertas F. Compatibility between superplasticizer admixtures and cements with mineral additions. Constr Build Mater 2012;31:300-9.

41. Pointeau I, Reiller P, Macé N, Landesman C, Coreau N. Measurement and modeling of the surface potential evolution of hydrated cement pastes as a function of degradation. J Colloid Interface Sci 2006;300:33-44.

42. Au P, Leong Y. Rheological and zeta potential behaviour of kaolin and bentonite composite slurries. Colloids Surf Physicochem Eng Aspects 2013;436:530-41.

43. Tombácz E, Szekeres M. Surface charge heterogeneity of kaolinite in aqueous suspension in comparison with montmorillonite. Appl Clay Sci 2006;34:105-24.

44. Lagaly G. Principles of flow of kaolin and bentonite dispersions. Appl Clay Sci $1989 ; 4: 105-23$.

45. Labbez C, Pochard I, Jönsson B, Nonat A. C-S-H/solution interface: Experimental and Monte Carlo studies. Cem Concr Res 2011;41:161-8.

Table 1. Characterization parameters of the superplasticizers assayed.

\begin{tabular}{cccccc}
\hline Polycarboxylate & $\begin{array}{c}\boldsymbol{C}, \boldsymbol{H} \\
\text { analysis } \\
(\%)\end{array}$ & $\begin{array}{c}\text { Number Average } \\
\text { Molecular Weight, } \\
\text { Mn }\left(g \mathrm{~mol}^{-1}\right)\end{array}$ & $\begin{array}{c}\text { Weight Average } \\
\text { Molecular Weight, } \\
\mathbf{M w}\left(\mathrm{g} \mathrm{mol} l^{-1}\right)\end{array}$ & $\begin{array}{c}\text { Polydispersity } \\
\text { index } \\
(P D I)\end{array}$ & $\begin{array}{c}\text { Anionic } \\
\text { charge density } \\
\left(\mathrm{meq}^{-1}\right)\end{array}$ \\
\hline PCE1 & $47.6 ; 7.6$ & 4,300 & 8,000 & 1.95 & $0.92 \pm 0.07$ \\
PCE2 & $21.4 ; 4.4$ & 2,900 & 5,700 & 1.94 & $1.30 \pm 0.06$ \\
\hline
\end{tabular}




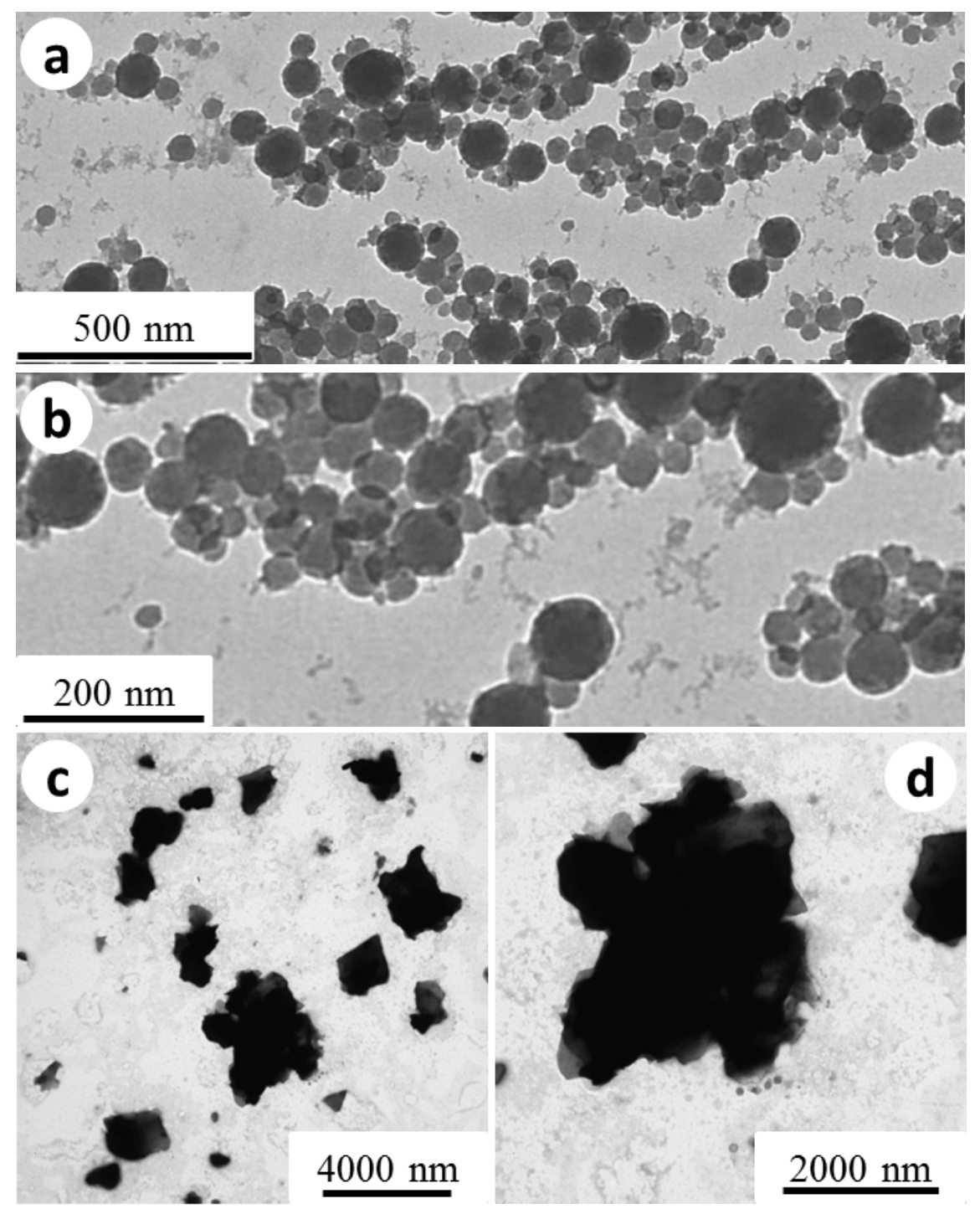

Figure 1. TEM micrographs of: a) and b) NS spherical particles; c) and d) MK particles with hexagonal layers and card-house agglomerations. 


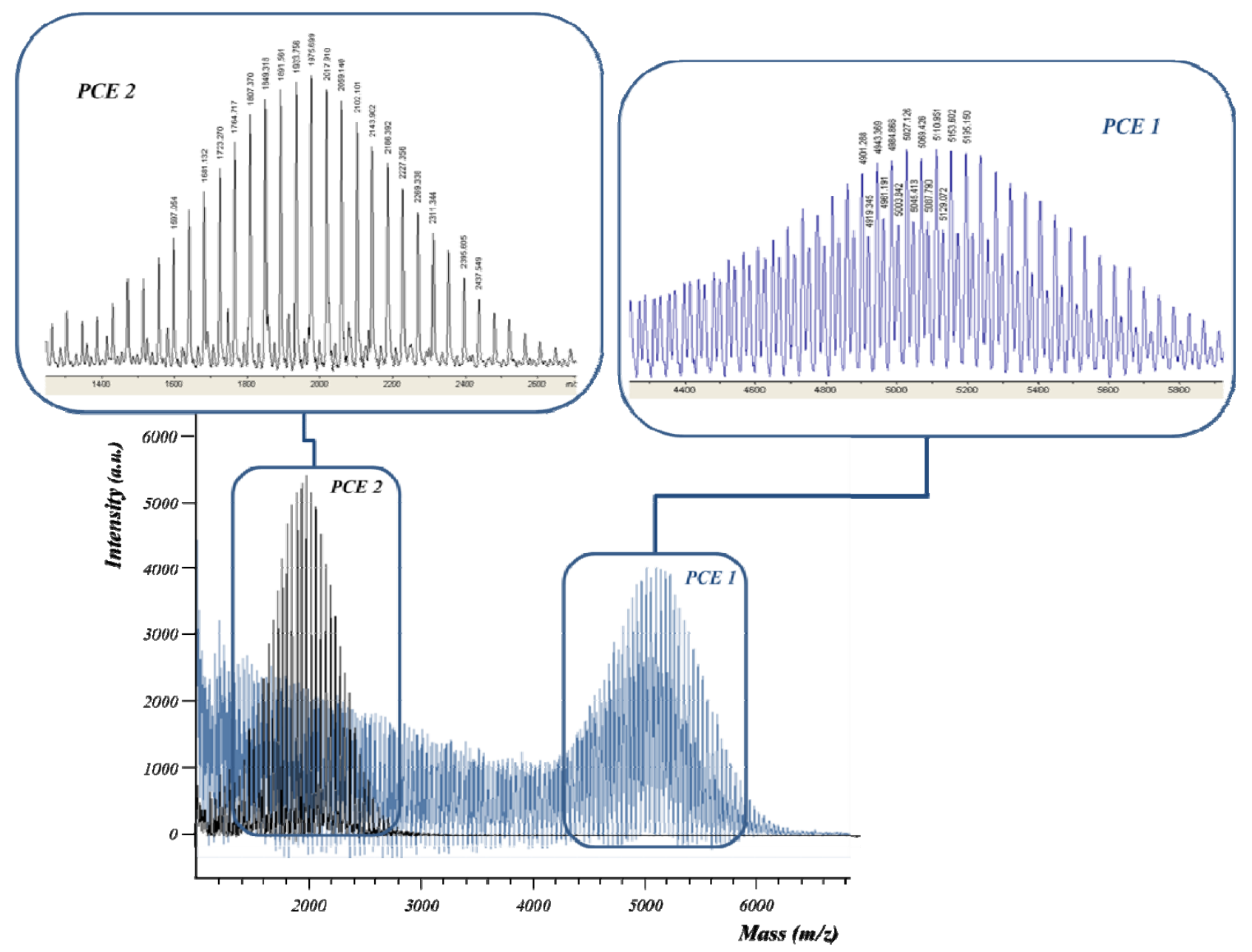

Figure 2. MALDI-TOF MS spectra of the two superplasticizers analysed.
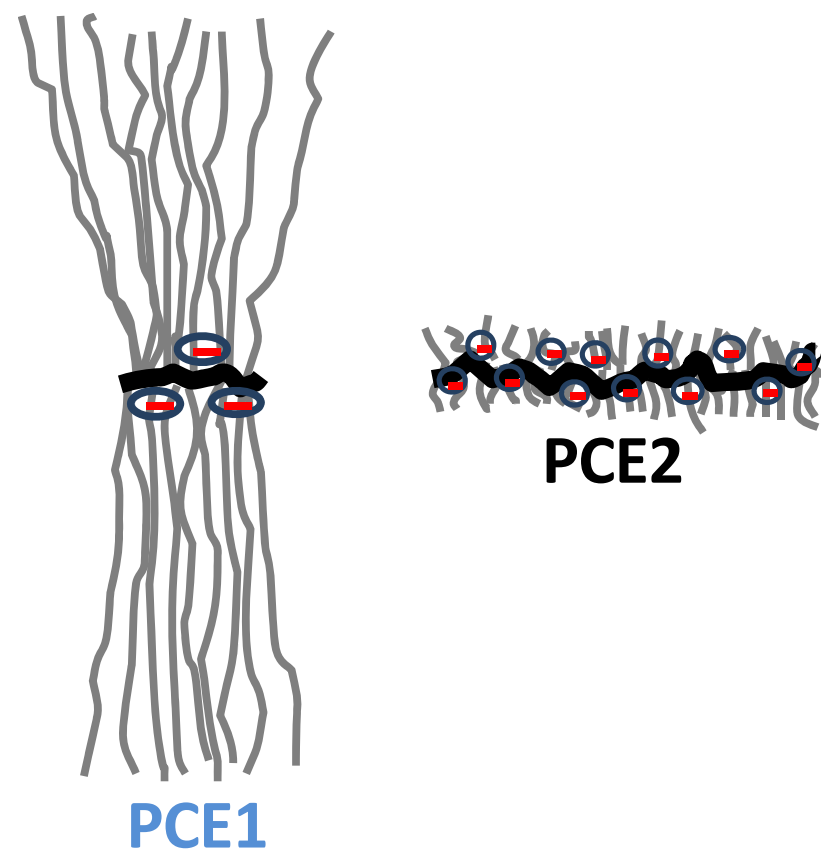

Figure 3. Schematic representation of the molecular architecture proposed for both PCEs. The main backbone shows the negative charges of the $\mathrm{COO}^{-}$groups. 


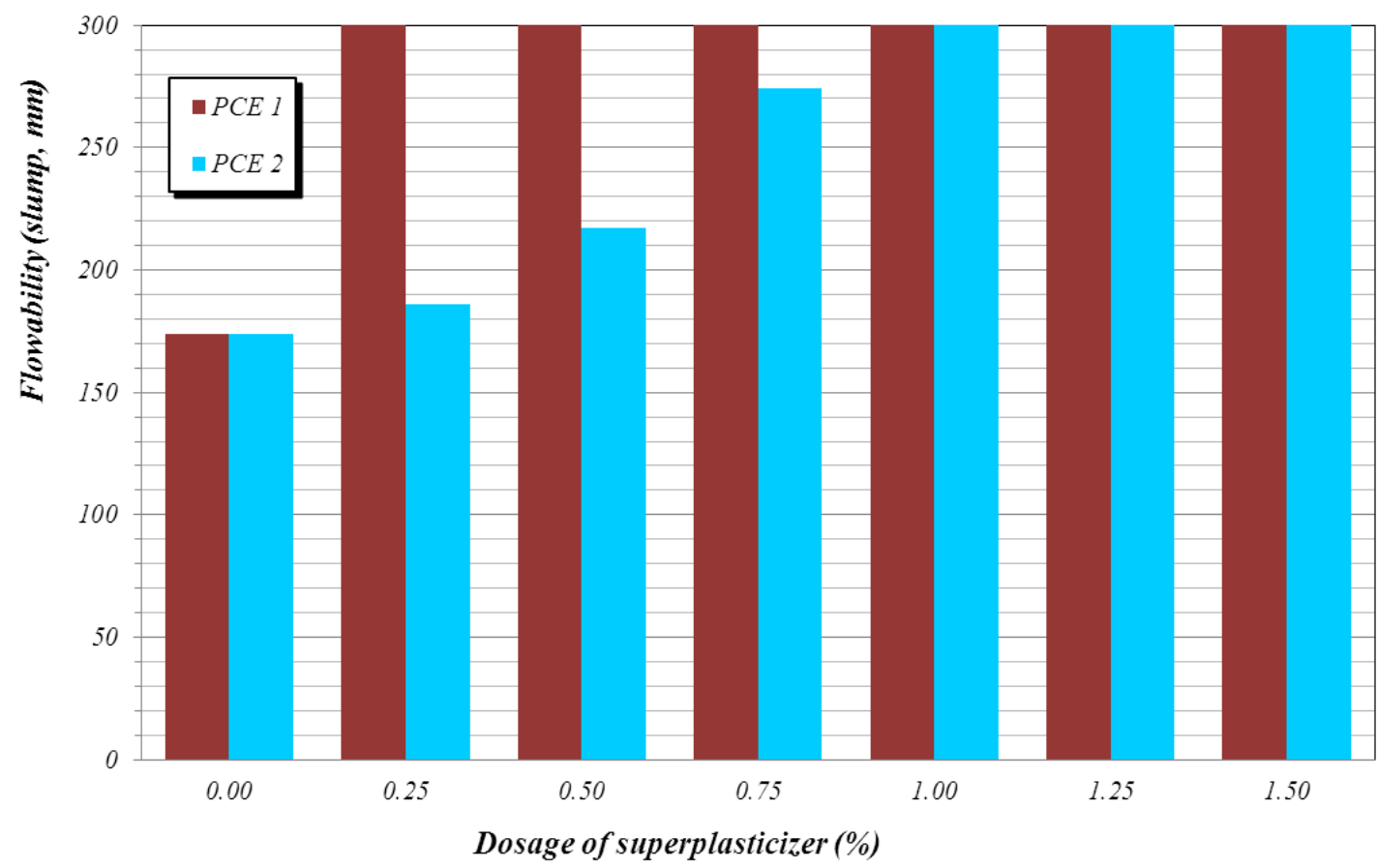

Figure 4. Flowability of the plain lime pastes vs. increasing amount of polycarboxylate ranging from $0 \%$ to $1.50 \%$ with respect to lime. 

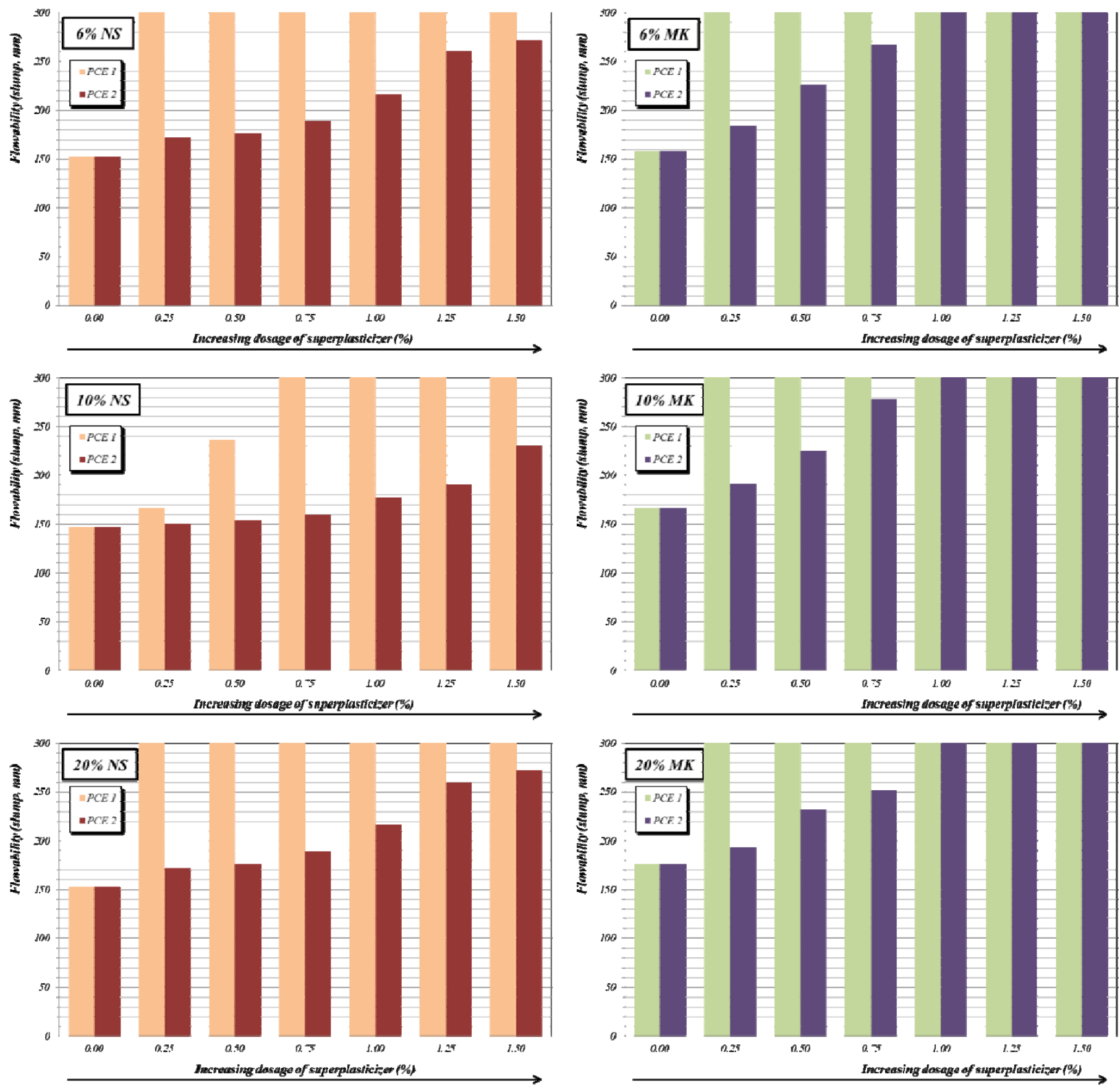

Figure 5. Flowability of the NS- (left) or MK-loaded (right) hydrated lime pastes at different percentages of pozzolanic additions vs. increasing amount of the tested superplasticizers (dosages from $0 \%$ to $1.50 \%$ with respect to lime). 

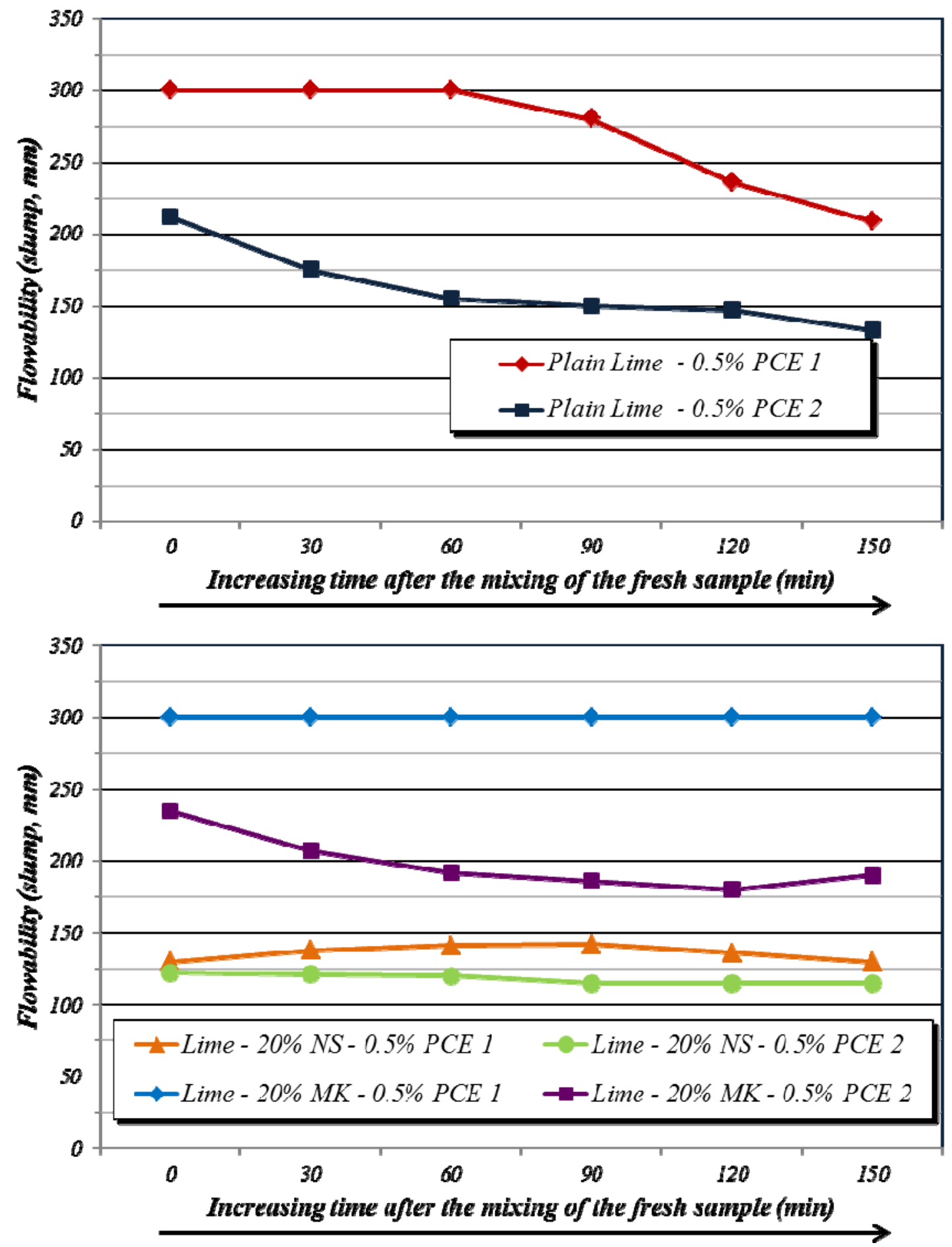

Figure 6. Dispersion maintaining ability over time of pastes with 0.5 wt. \% of SPs admixtures: plain lime (a) and lime modified upon the addition of nanosilica or metakaolin (b). 

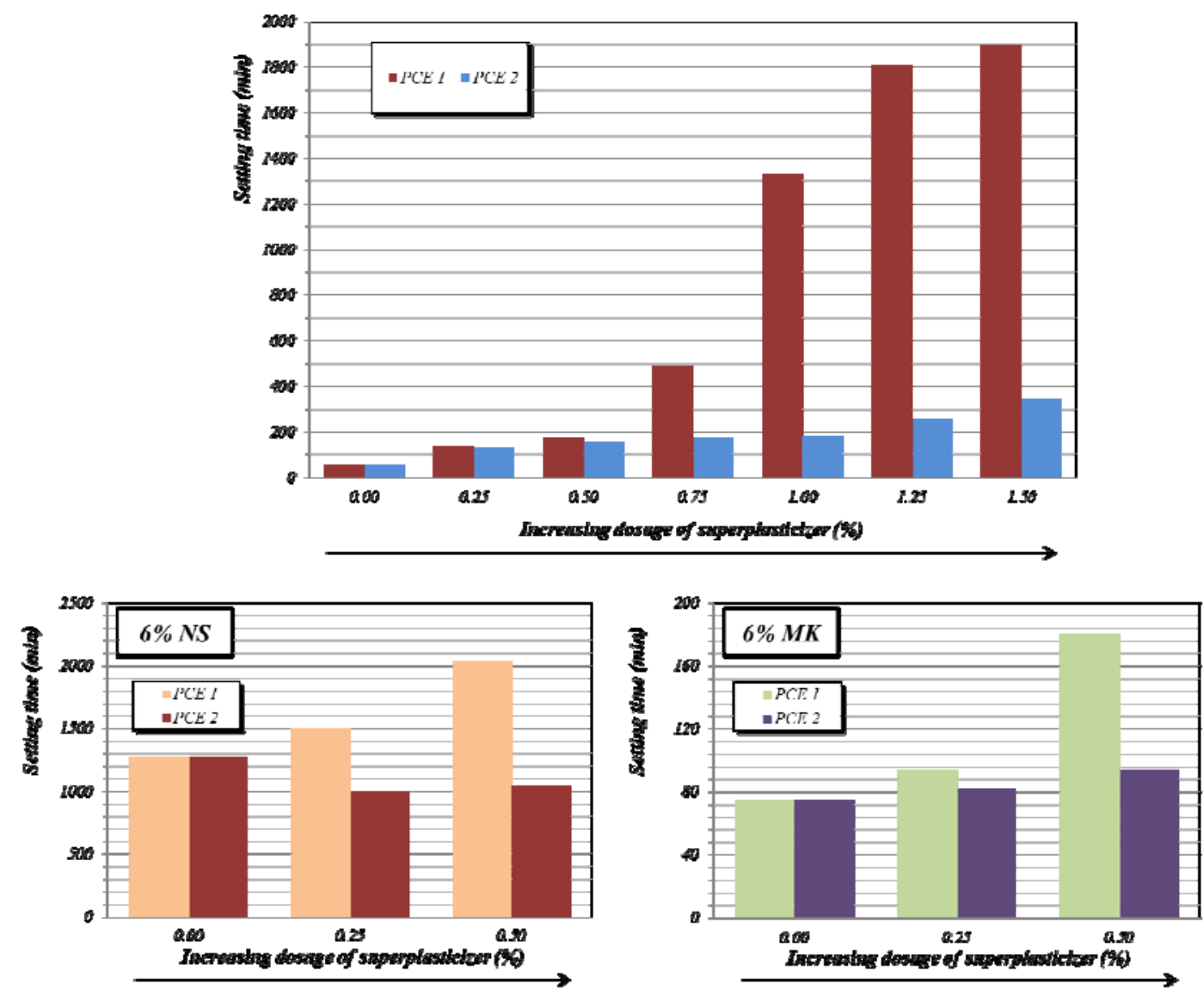

b
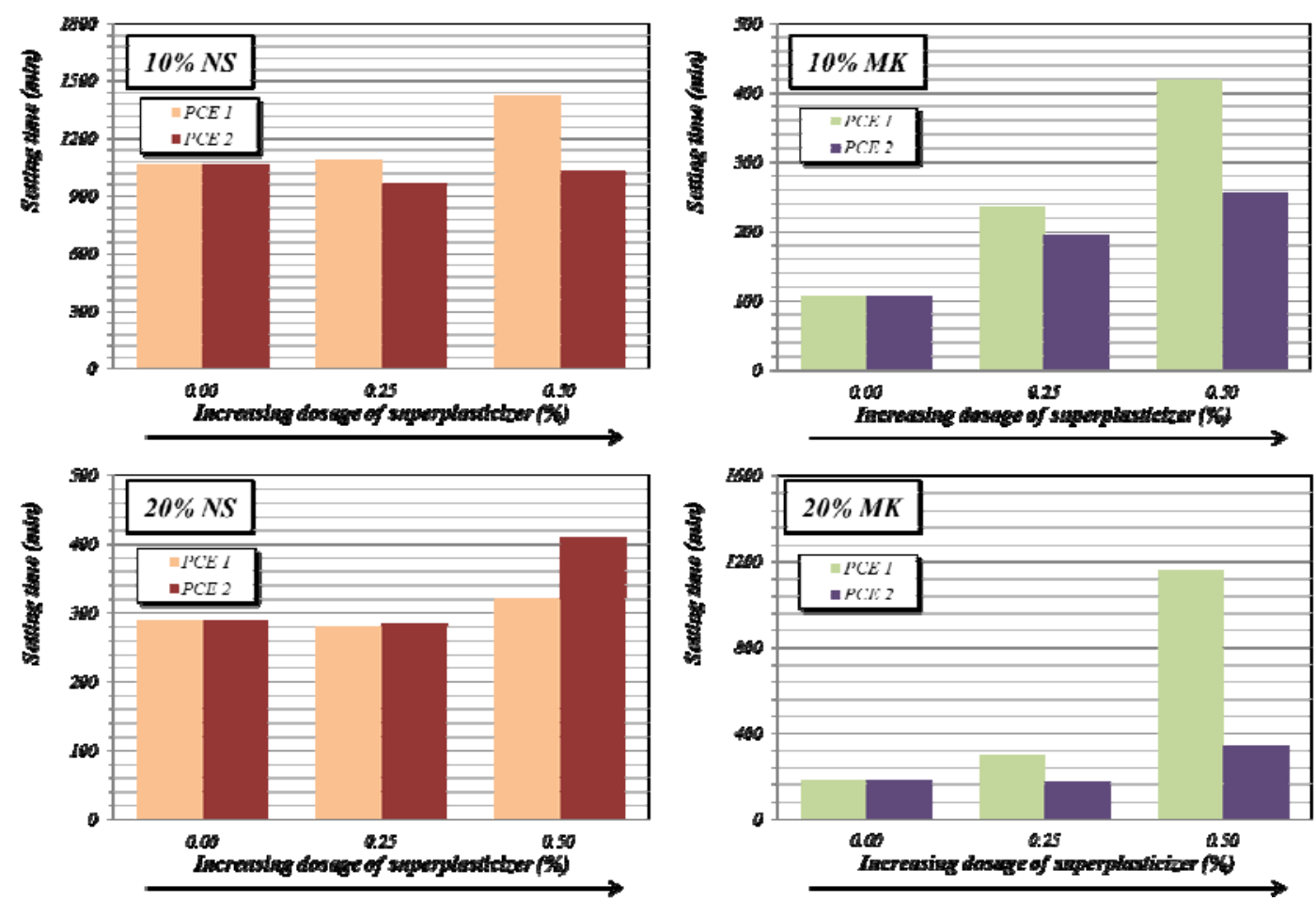

Figure 7. Setting time of: (a) plain lime pastes vs. increasing amounts of superplasticizers; (b) NS- or MK-bearing pastes vs. increasing amounts of superplasticizers (dosages ranging from 0 to $0.50 \mathrm{wt} . \%$ with respect to lime) (in these samples dosages above $0.50 \%$ of SPs induced such strong delays in the setting time that were not fully registered and, consequently, are not shown). 


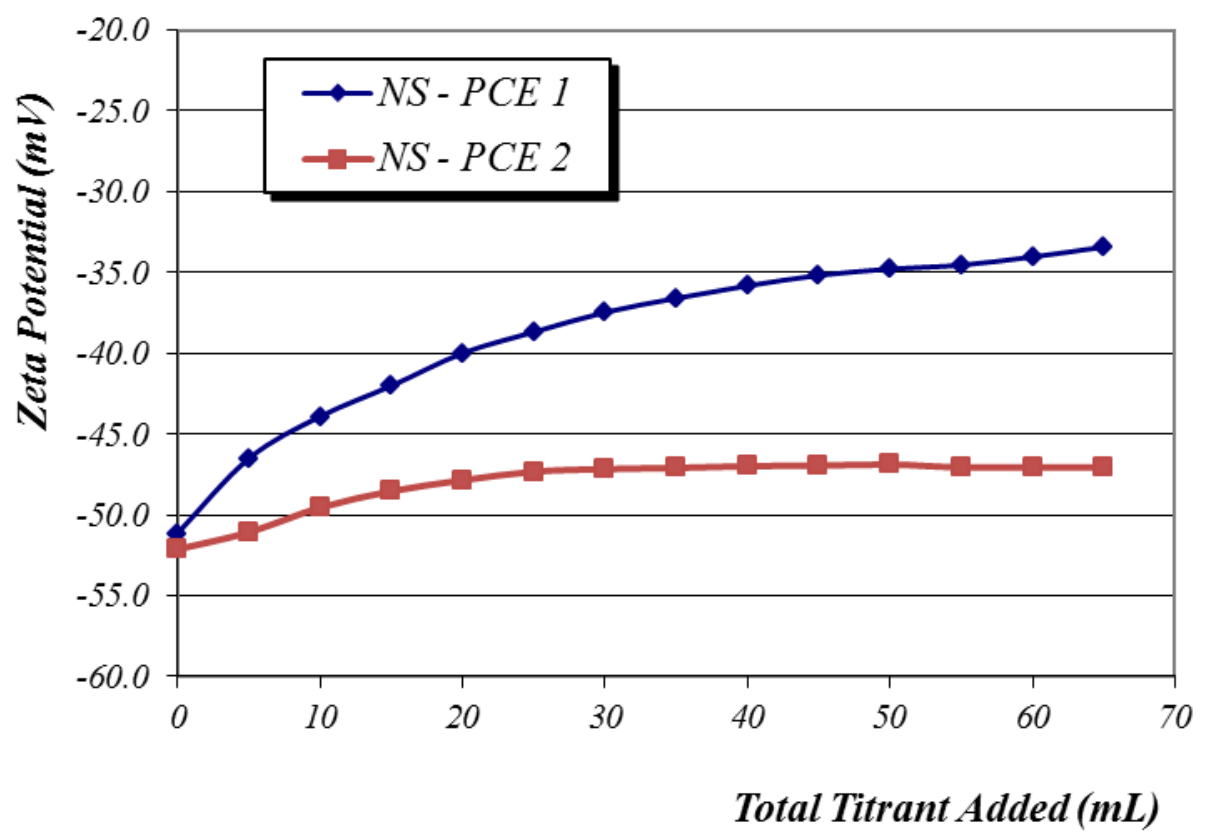

Figure 8. Zeta potential values of plain nanosilica suspensions titrated with superplasticizers assayed. 


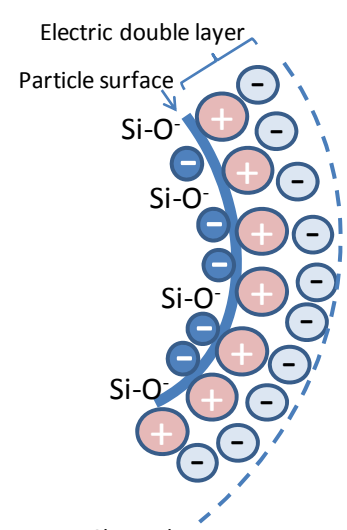

Shear plané

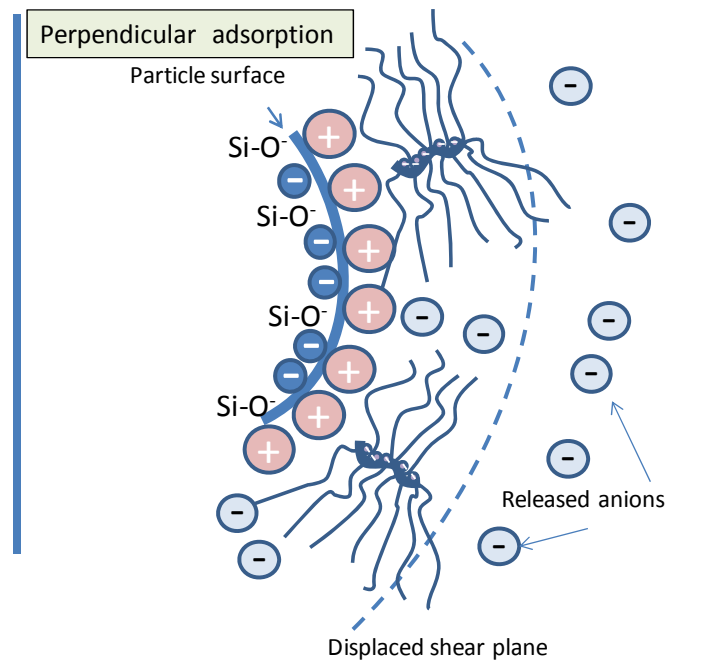

Displaced shear plane

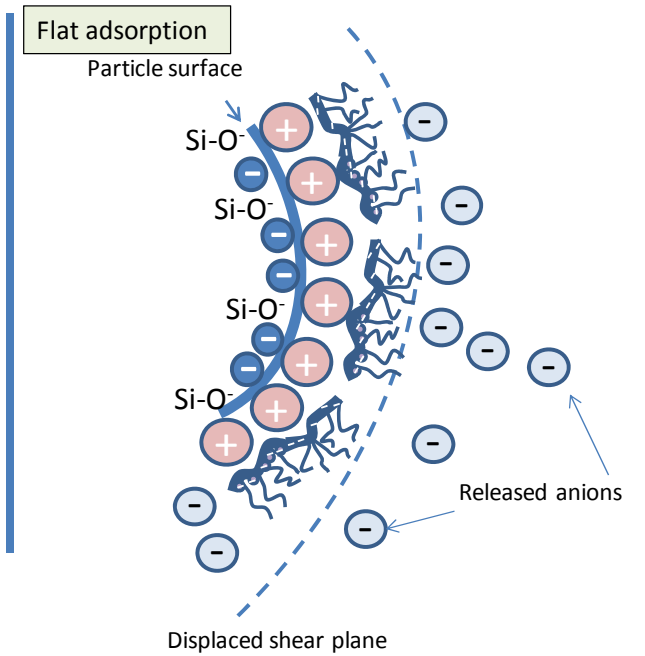

Displaced shear plane

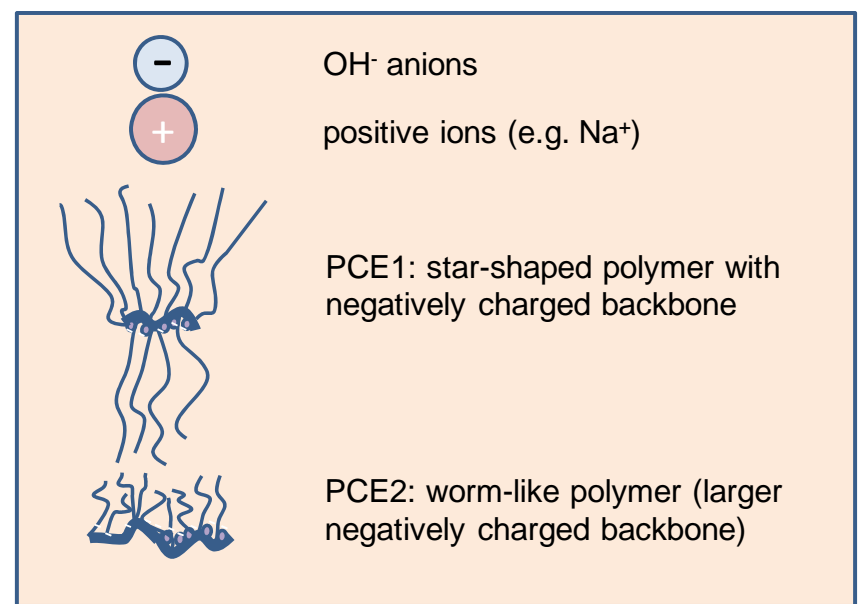

Figure 9. Electric double layer of the particles of nanosilica in a colloidal suspension (left). Adsorption model of PCE1 onto NS particles showing a strong displacement of the shear plane of the EDL (center). Flat adsorption with a higher surface loading of worm-like PCE2 onto NS particles, resulting in a less pronounced displacement of the shear plane. 


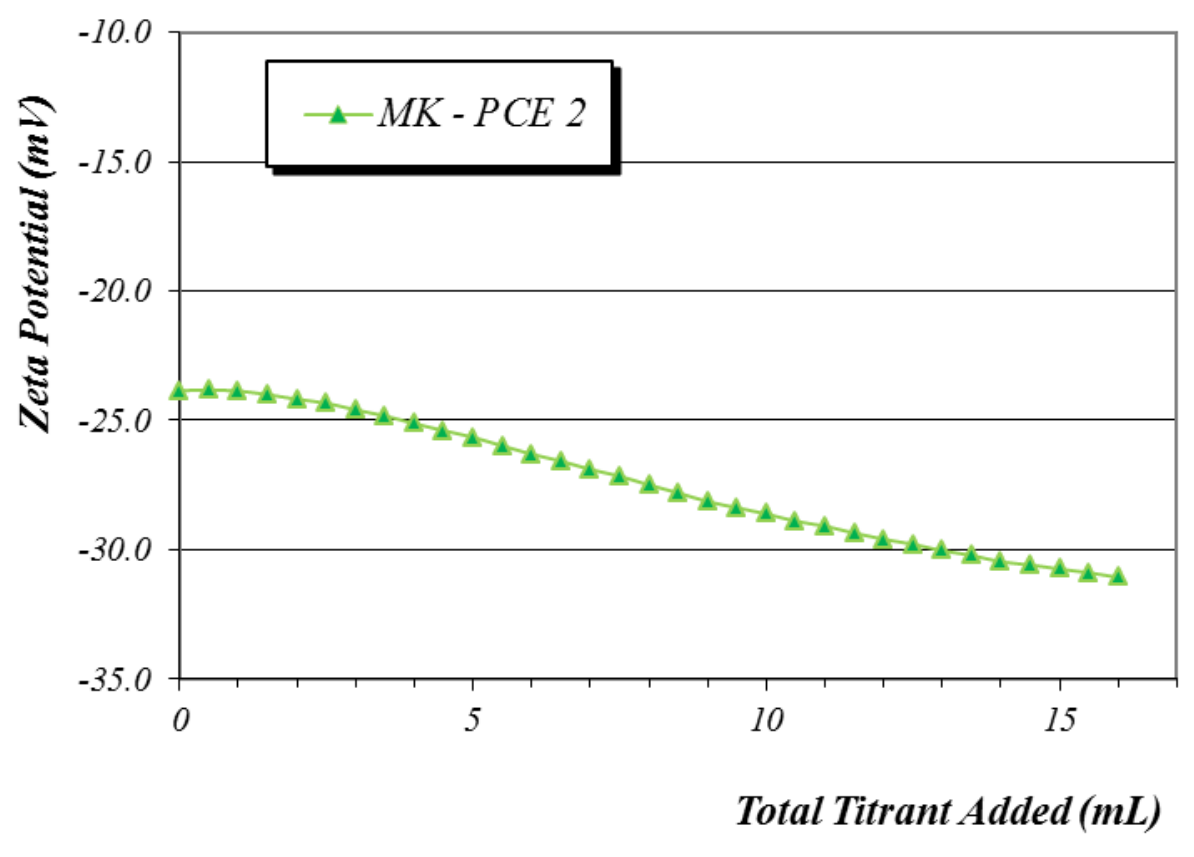

Figure 10. Zeta potential values of a plain metakaolin suspension titrated with PCE2.

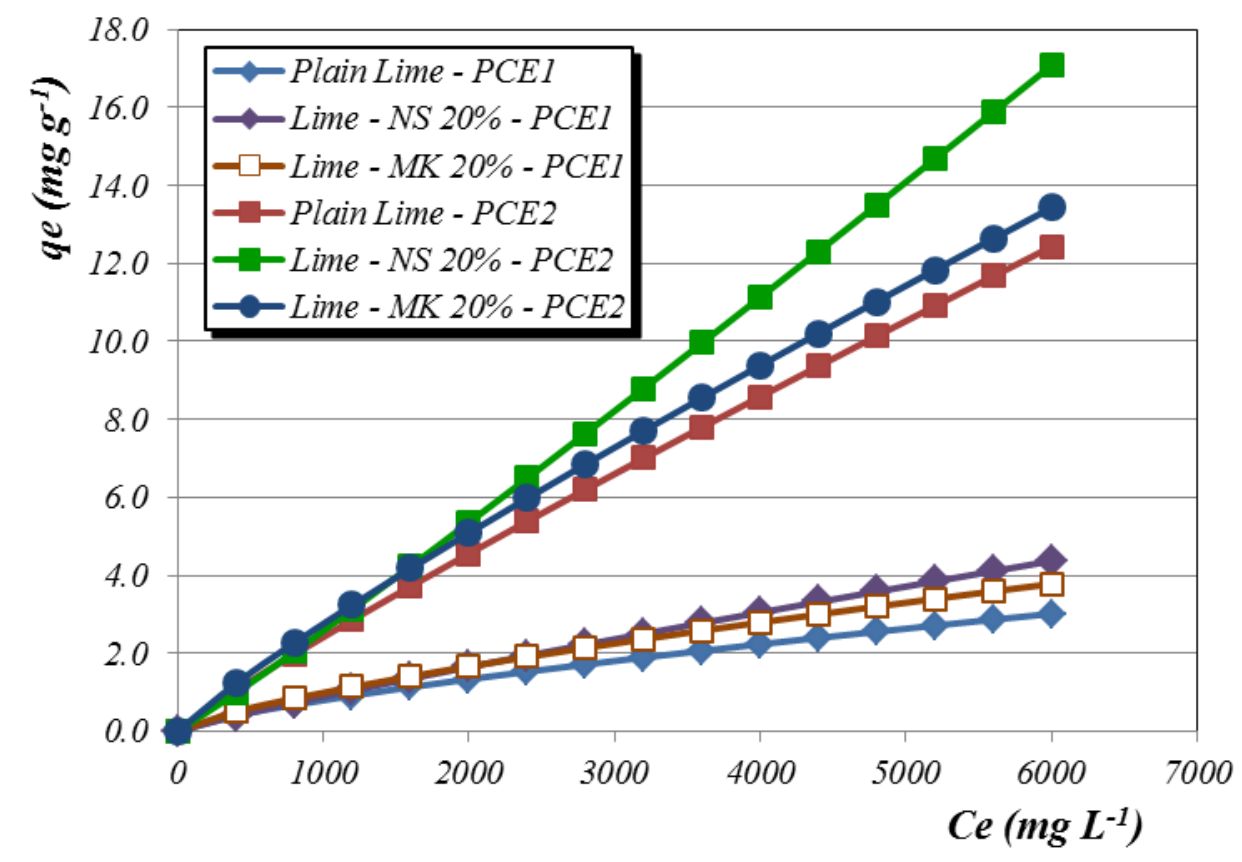

Figure 11. Adsorption isotherms of the superplasticizers assayed onto plain lime, limeNS and lime-MK pastes ( $20 \mathrm{wt} . \%$ of pozzolanic additive) fitted acording to Freunlich model. 


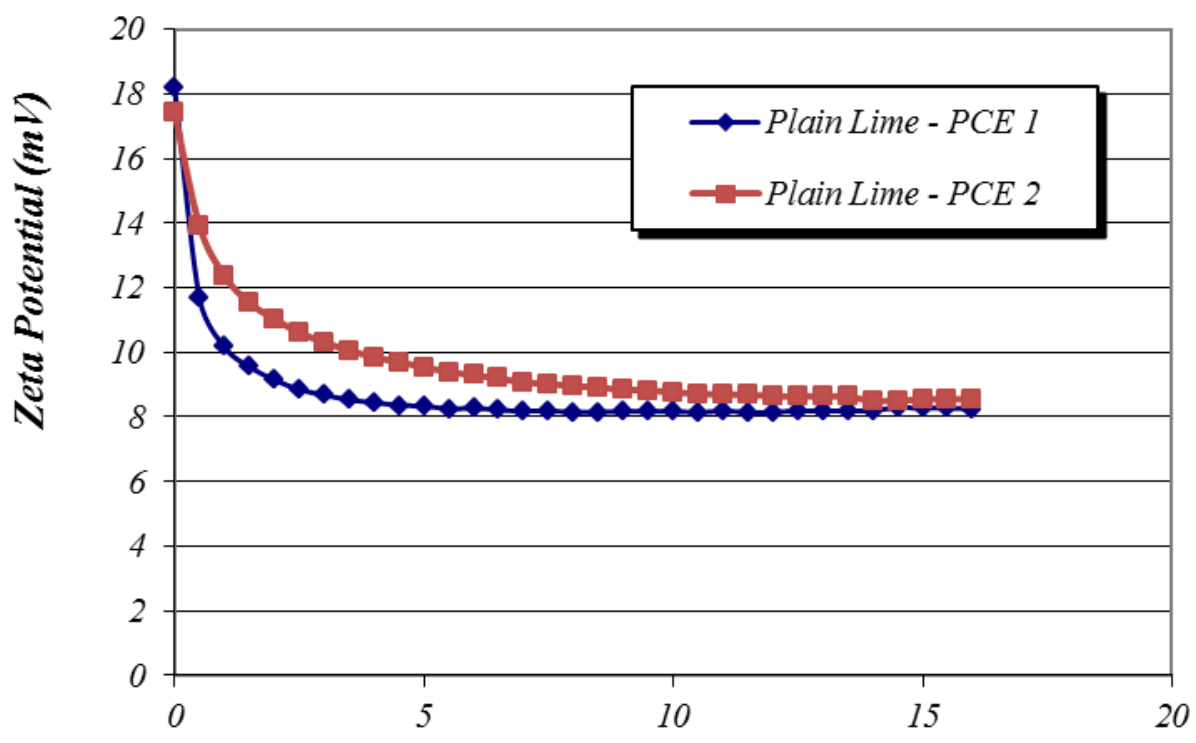

Total Titrant Added (mL)

Figure 12. Zeta potential values of plain lime pastes titrated with the two superplasticizers assayed.

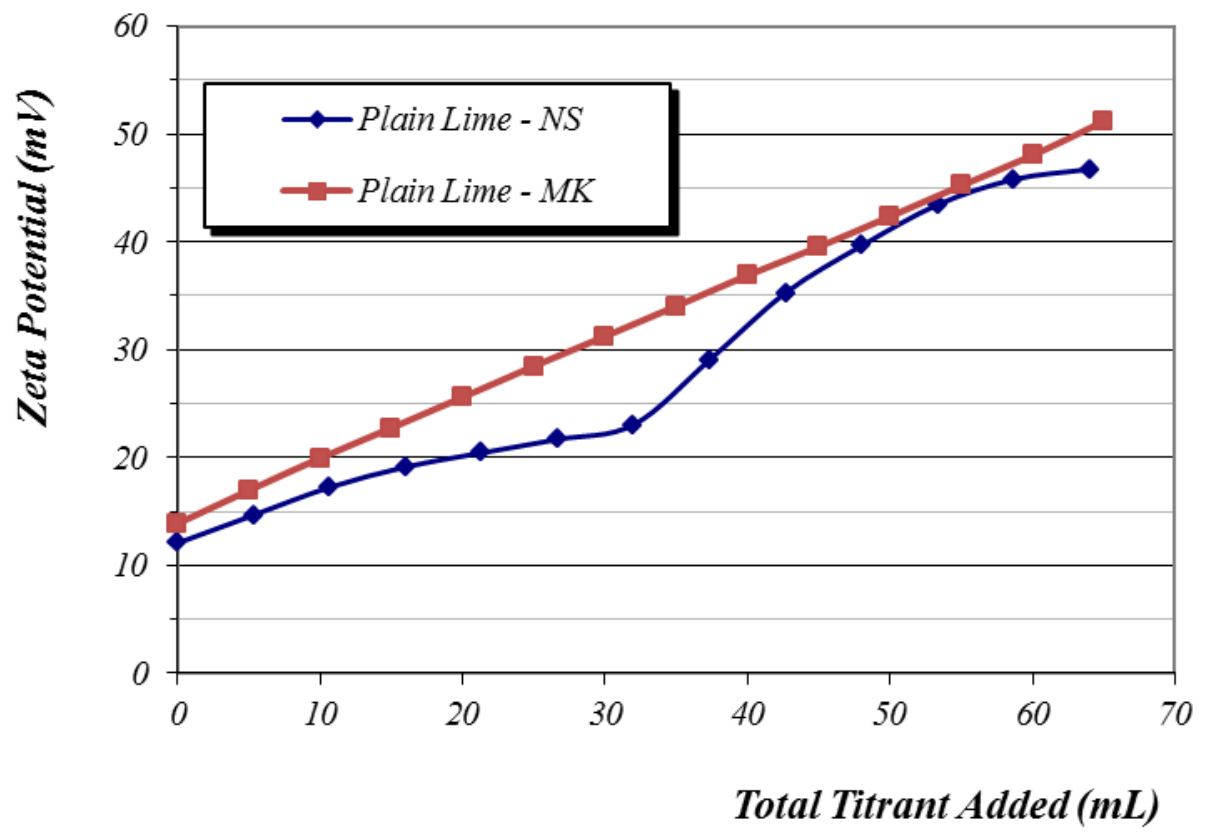

Figure 13. Zeta potential of air lime pastes versus increasing amounts of NS or MK. 


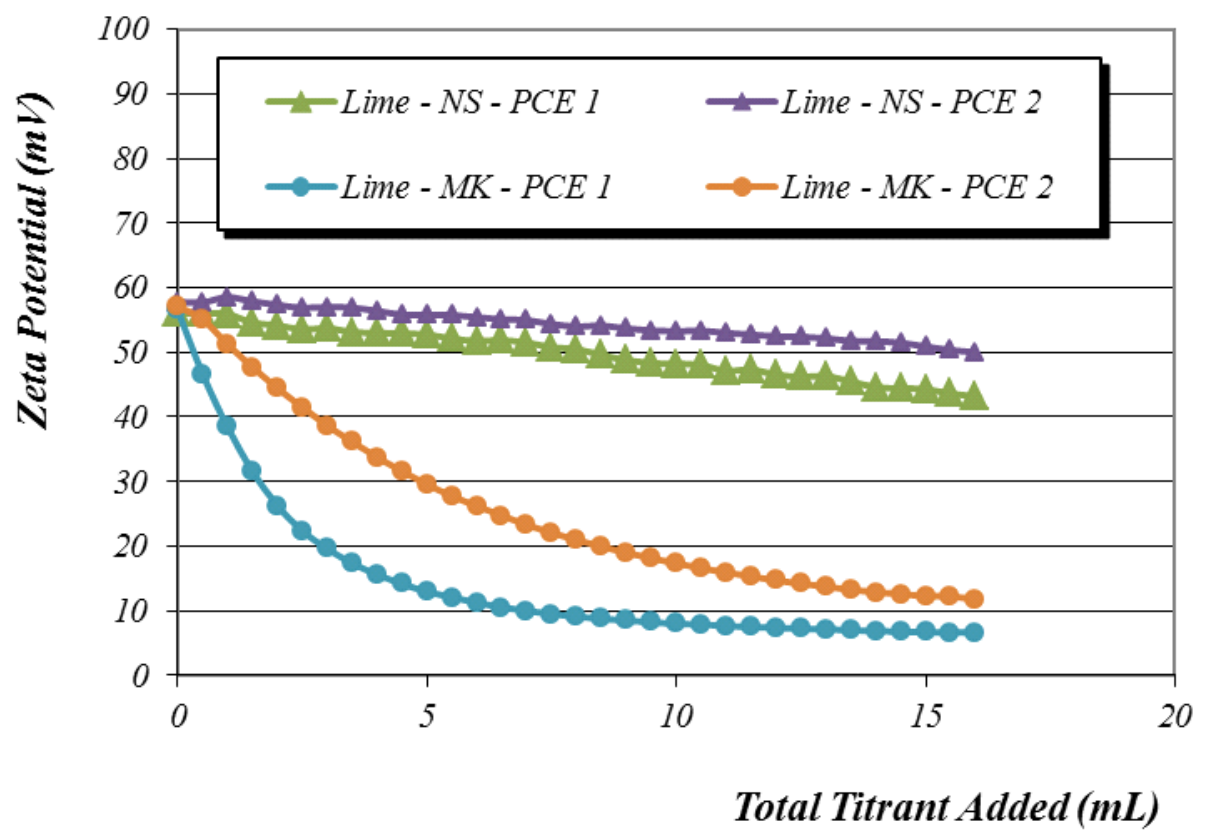

Figure 14. Zeta potential of lime-NS and lime-MK pastes titrated with the superplasticizers assayed.

\section{Supplementary material}

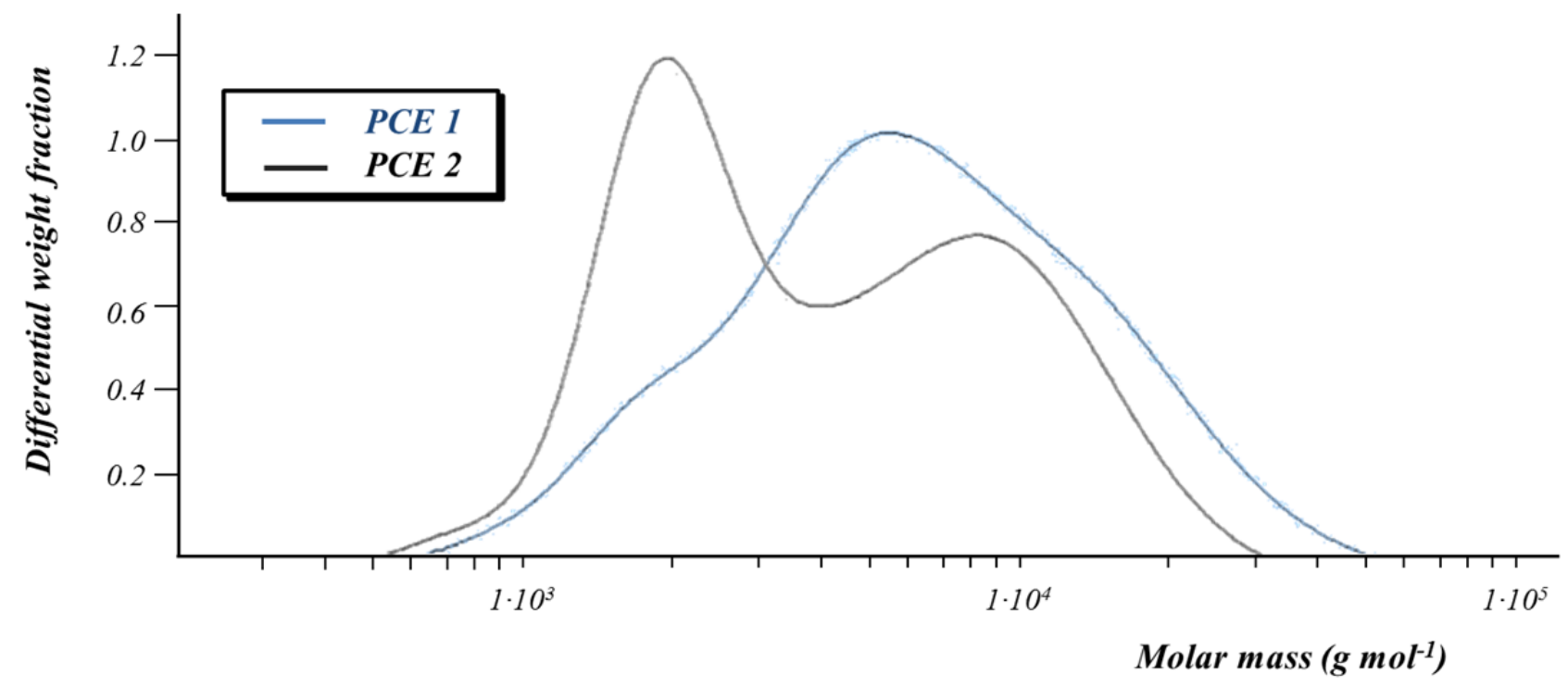

Figure S1. Size exclusion chromatography results: differential weight fraction of the two superplasticizers analysed. 
g: Polyethylene glycol 4000, $\mathrm{PEG} 4000, \mathrm{C}_{136} \mathrm{H}_{274} \mathrm{O}_{69} / \mathrm{H}\left(\mathrm{OCH}_{2} \mathrm{CH}_{2}\right)_{68} \mathrm{OH}$, ICDD 00-049-2095

P: Polyethylene glycol 6000, $\mathrm{PEG}$ 6000, $\mathrm{C}_{316} \mathrm{H}_{634} \mathrm{O}_{159} / \mathrm{H}\left(\mathrm{OCH}_{2} \mathrm{CH}_{2}\right)_{x} \mathrm{OH}, \mathrm{ICDD}$ 00-049-2109

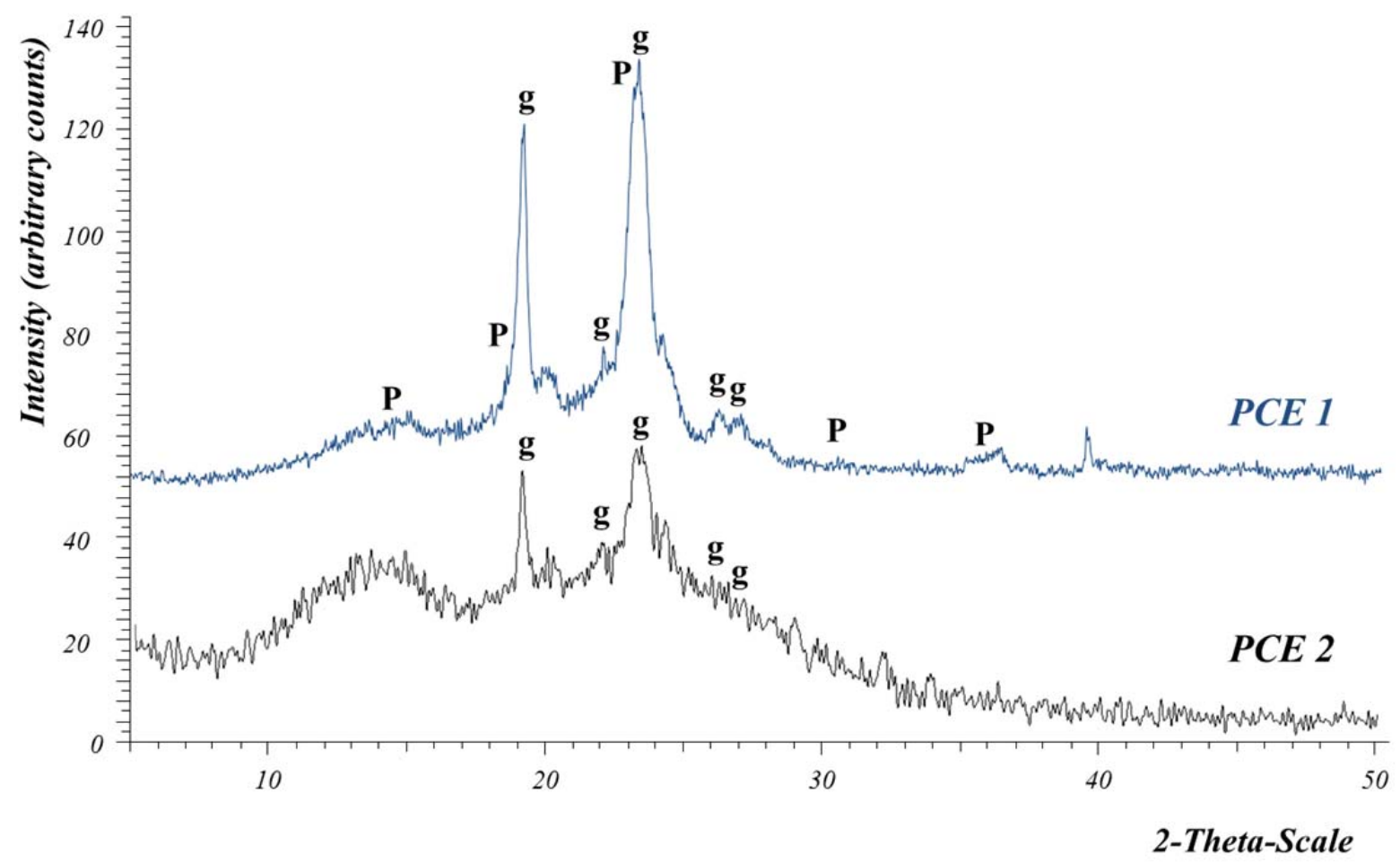

Figure S2. XRD analysis of the superplasticizers tested identifying the main diffraction peaks of the grafted side chains of the polyethylene glycol.

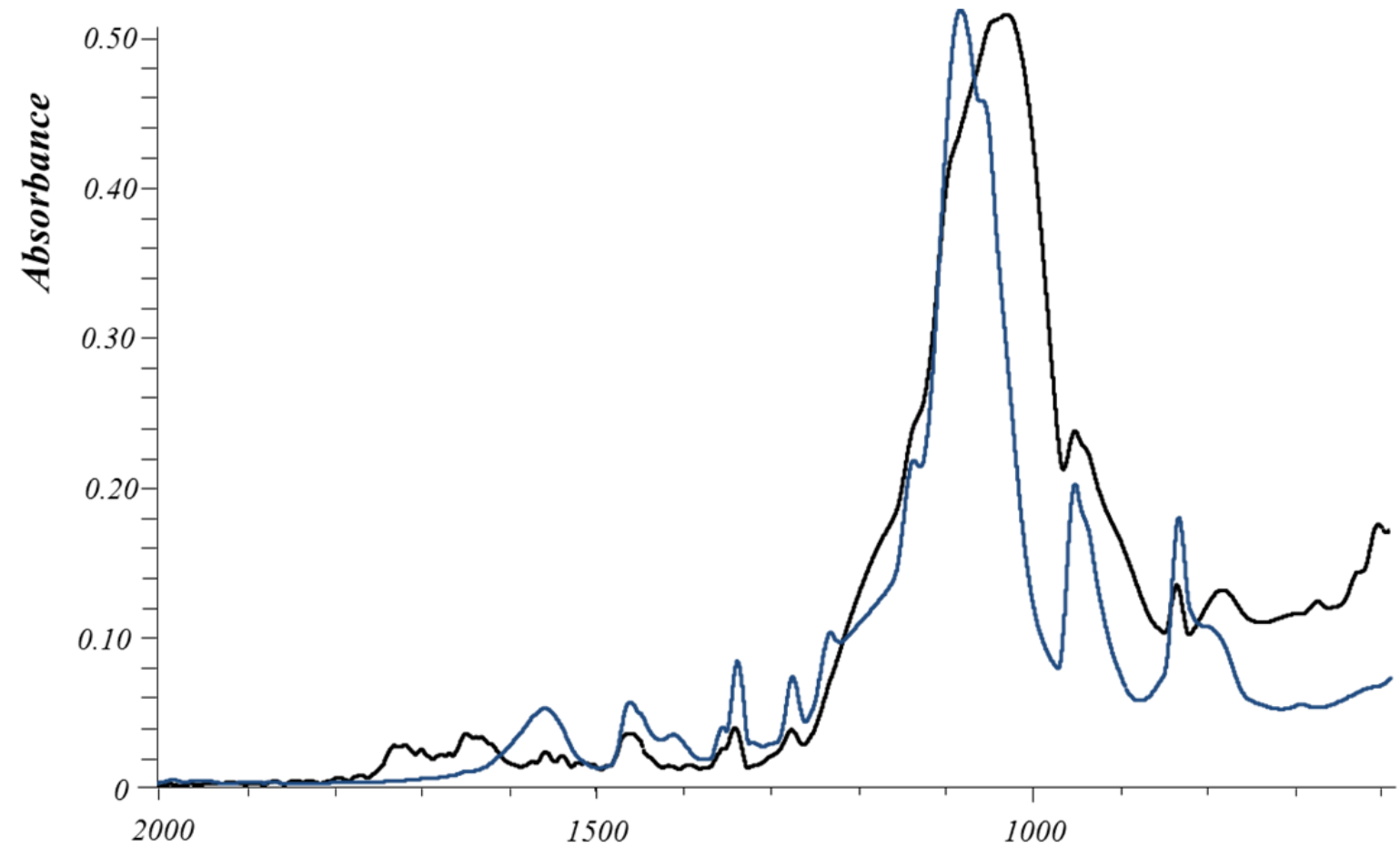

PCE 2

Wavenumbers $\left(\mathrm{cm}^{-1}\right)$

Figure S3. FTIR spectra of the superplasticizers assayed. 